\title{
Enantioselective Rauhut-Currier Reactions Promoted By Protected Cysteine
}

Carrie E. Aroyan and Scott J. Miller*

Department of Chemistry, Merkert Chemistry Center, Boston College, Chestnut Hill, Massachusetts 02467-3860 and Department of Chemistry, Yale University, P.O. Box 208107, New Haven, CT 06520-8107

Email: scott.miller@yale.edu

\section{Supporting Information}

General Procedures. Proton NMR spectra were recorded on a 500 or $400 \mathrm{MHz}$ spectrometer. Proton chemical shifts are reported in ppm $(\delta)$ relative to internal tetramethylsilane (TMS, $\delta 0.0$ $\mathrm{ppm})$ or with the solvent reference relative to TMS employed as the internal standard $\left(\mathrm{CDCl}_{3}, \delta\right.$ $\left.7.26 \mathrm{ppm} ; \mathrm{d}_{6}-\mathrm{DMSO}, \delta 2.50 \mathrm{ppm} ; \mathrm{CD}_{3} \mathrm{OD}, \delta 3.31 \mathrm{ppm} ; \mathrm{D}_{2} \mathrm{O}, \delta 4.79 \mathrm{ppm}\right)$. Data are reported as follows: chemical shift (multiplicity [singlet (s), doublet (d), triplet (t), quartet (q), and multiplet (m)], coupling constants [Hz], integration). Carbon NMR spectra were recorded at 125 or 100 $\mathrm{MHz}$ with complete proton decoupling. Carbon chemical shifts are reported in ppm $(\delta)$ relative to TMS with the respective solvent resonance as the internal standard $\left(\mathrm{CDCl}_{3}, \delta 77.0 \mathrm{ppm}\right)$. Infrared spectra were obtained on a Perkin-Elmer Spectrum 1000 spectrometer. Analytical thinlayer chromatography (TLC) was performed using Silica Gel $60 \AA$ F254 precoated plates $(0.25$ $\mathrm{mm}$ thickness). TLC $\mathrm{R}_{f}$ values are reported. Visualization was accomplished by irradiation with a UV lamp and/or staining with $\mathrm{KMnO}_{4}$ or cerium ammonium molybdenate (CAM) solutions. Flash column chromatography was performed using Silica Gel $60 \AA(32-63 \mu \mathrm{m}){ }^{\mathrm{i}}$ Optical rotations were recorded on a Rudolf Research Analytical Autopol IV Automatic polarimeter at the sodium D line (path length $100 \mathrm{~mm}$ ). High resolution mass spectra were obtained at the Mass Spectrometry Facility of either Boston College (Chestnut Hill, MA) or the University of Illinois (Urbana-Champaign, IL). The method of ionization is given in parentheses.

Analytical normal phase HPLC was performed on a Hewlett-Packard 1100 Series chromatograph equipped with a diode array detector $(214 \mathrm{~nm}$ and $254 \mathrm{~nm})$. All reactions were carried out under an argon or nitrogen atmosphere employing oven- and flame-dried glassware. All solvents were purified using a Seca Solvent Purification System by GlassContour. $t$-BuOK was freshly sublimed prior to use. 
General Procedure A: Preparation of Intramolecular Rauhut-Currier Substrates (1a-d, 9, 11, 13).
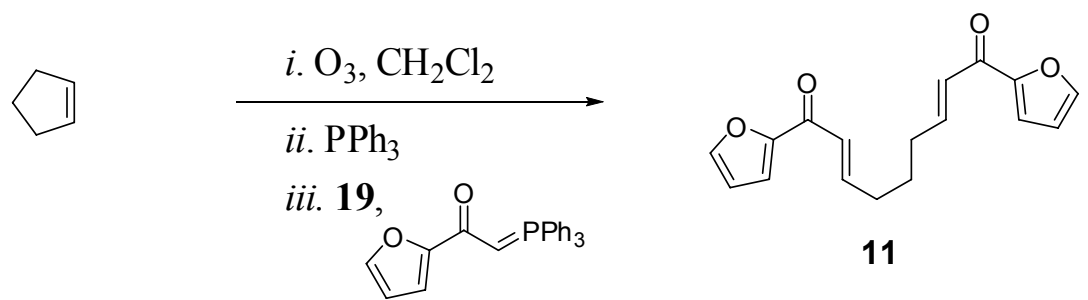

(11). Cyclopentene $(520 \mu \mathrm{L}, 5.9 \mathrm{mmol})$ was dissolved in $\mathrm{CH}_{2} \mathrm{Cl}_{2}(8.7 \mathrm{~mL})$, cooled to $-78{ }^{\circ} \mathrm{C}$, and ozone was bubbled through the reaction until the clear solution turned blue. Nitrogen was then bubbled through the solution until the blue color disappeared to remove excess ozone. Triphenylphosphine $(2.3 \mathrm{~g}, 8.9 \mathrm{mmol})$ was added and the reaction was allowed to stir for $1 \mathrm{~h}$ at $-78^{\circ} \mathrm{C}$. Stabilized ylide 19 (4.6 g, $\left.12.4 \mathrm{mmol}\right)$ was added at room temperature and the pale yellow solution was allowed to stir for $24 \mathrm{~h}$ and then concentrated. Flash chromatography of the crude material (hexanes-EtOAc, 5:1) gave 11 as a pale yellow oil (790 mg, 2.8 mmol, 47\%). Compounds 1a-d, 9, and $\mathbf{1 3}$ were prepared by analogous methodology.

(11).<smiles>O=C(/C=C/CCC/C=C/C(=O)c1ccco1)c1ccco1</smiles>

11

${ }^{1} \mathrm{H} \mathrm{NMR}\left(\mathrm{CDCl}_{3}, 400 \mathrm{MHz}\right) \delta$ 7.63-7.62 (m, 2H), 7.27-7.24 (m, 2H), $7.15(\mathrm{dt}, J=15.4,7.2 \mathrm{~Hz}$, $2 \mathrm{H}), 6.84(\mathrm{~d}, J=15.6 \mathrm{~Hz}, 2 \mathrm{H}), 6.56(\mathrm{dd}, J=3.5,1.8 \mathrm{~Hz}, 2 \mathrm{H}), 2.38(\mathrm{q}, J=6.8 \mathrm{~Hz}, 4 \mathrm{H}), 1.78$ (quintet, $J=7.5 \mathrm{~Hz}, 2 \mathrm{H})$; ${ }^{13} \mathrm{C} \mathrm{NMR}\left(\mathrm{CDCl}_{3}, 125 \mathrm{MHz}\right) \delta 178.3,153.7,148.1,146.9,125.9$, 118.0, 112.7, 32.4, 26.9; IR (film, cm ${ }^{-1}$ ) 3124, 2933, 1664, 1620, 1564, 1465, 1392, 1297, 1010; TLC $\mathrm{R}_{f} 0.25$ (2:1 hexanes-EtOAc); HRMS (ESI) $\mathrm{m} / z 285.1137$ (285.1127 calcd for $\mathrm{C}_{17} \mathrm{H}_{17} \mathrm{O}_{4}$ $\left.[\mathrm{M}+\mathrm{H}]^{+}\right)$.

(1a).

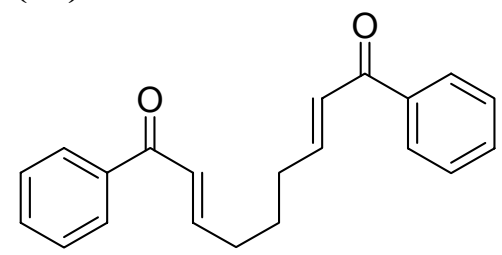

$1 a$

${ }^{1} \mathrm{H} \mathrm{NMR}\left(\mathrm{CDCl}_{3}, 500 \mathrm{MHz}\right) \delta 7.93(\mathrm{dd}, J=8.2,1.2 \mathrm{~Hz}, 4 \mathrm{H}), 7.55(\mathrm{t}, J=7.5 \mathrm{~Hz}, 2 \mathrm{H}), 7.46(\mathrm{t}, J$ $=7.6 \mathrm{~Hz}, 4 \mathrm{H}), 7.06(\mathrm{dt}, J=15.4,6.9 \mathrm{~Hz}, 2 \mathrm{H}), 6.92(\mathrm{~d}, J=15.4 \mathrm{~Hz}, 2 \mathrm{H}), 2.39$ (q, $J=6.8 \mathrm{~Hz}, 4 \mathrm{H})$, $1.83-1.75(\mathrm{~m}, 2 \mathrm{H}) ;{ }^{13} \mathrm{C} \mathrm{NMR}\left(\mathrm{CDCl}_{3}, 125 \mathrm{MHz}\right) \delta 190.6,148.5,137.8,132.7,128.5,128.4$, 126.4, 32.1, 26.7; IR (film, $\mathrm{cm}^{-1}$ ) 3056, 2929, 2856, 1671, 1621, 1577, 1446, 1344, 1291, 1221, 
1009, 968; TLC $\mathrm{R}_{f} 0.46$ (3:1 hexanes-EtOAc); HRMS (ESI) $\mathrm{m} / z 305.1546$ (305.1542 calcd for $\left.\mathrm{C}_{21} \mathrm{H}_{21} \mathrm{O}_{2}[\mathrm{M}+\mathrm{H}]^{+}\right)$.

(1b).

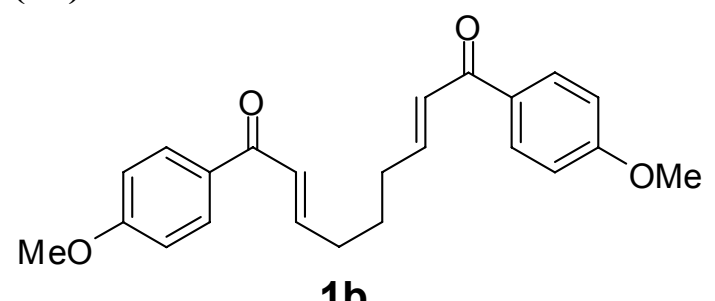

$1 \mathrm{~b}$

${ }^{1} \mathrm{H} \mathrm{NMR}\left(\mathrm{CDCl}_{3}, 400 \mathrm{MHz}\right) \delta 7.95(\mathrm{~d}, J=8.7 \mathrm{~Hz}, 4 \mathrm{H}), 7.05(\mathrm{dt}, J=15.2,6.9 \mathrm{~Hz}, 2 \mathrm{H}), 6.97-$ $6.90(\mathrm{~m}, 6 \mathrm{H}), 3.88(\mathrm{~s}, 6 \mathrm{H}), 2.39(\mathrm{q}, J=7.1 \mathrm{~Hz}, 4 \mathrm{H}), 1.78$ (quintet, $J=7.4 \mathrm{~Hz}, 2 \mathrm{H}) ;{ }^{13} \mathrm{C}$ NMR $\left(\mathrm{CDCl}_{3}, 100 \mathrm{MHz}\right) \delta 188.8,163.4,147.5,130.8,130.7,126.2,113.8,55.5,32.1,26.8$; IR (film, $\left.\mathrm{cm}^{-1}\right) 3010,2930,2835,1662,1621,1594,1570,1506,1302,1259,1235,1167$; TLC R 0.26 (2:1 hexanes-EtOAc); HRMS (ESI) $\mathrm{m} / z 365.1764$ (365.1753 calcd for $\mathrm{C}_{23} \mathrm{H}_{25} \mathrm{O}_{4}[\mathrm{M}+\mathrm{H}]^{+}$).

(1c).<smiles>CC(C)(C)CC/C=C/C(=O)c1ccc(Br)cc1</smiles>

${ }^{1} \mathrm{H}$ NMR $\left(\mathrm{CDCl}_{3}, 500 \mathrm{MHz}\right) \delta 7.79(\mathrm{~d}, J=8.5 \mathrm{~Hz}, 4 \mathrm{H}), 7.61(\mathrm{~d}, J=8.5 \mathrm{~Hz}, 4 \mathrm{H}), 7.07(\mathrm{dt}, J=$ 15.1, $7.1 \mathrm{~Hz}, 2 \mathrm{H}), 6.82(\mathrm{~d}, J=15.1 \mathrm{~Hz}, 2 \mathrm{H}), 2.40(\mathrm{q}, J=6.8 \mathrm{~Hz}, 4 \mathrm{H}), 1.78$ (quintet, $J=7.5 \mathrm{~Hz}$, 2H); ${ }^{13} \mathrm{C} \mathrm{NMR}\left(\mathrm{CDCl}_{3}, 125 \mathrm{MHz}\right) \delta 189.3,149.0,136.5,131.9,130.0,127.9,126.0,32.2,26.6$; IR (film, $\mathrm{cm}^{-1}$ ) 2949, 2886, 2829, 2722, 1721, 1671, 1620, 1583, 1400, 1073, 1010; TLC R $\mathrm{R}_{f} 0.42$ (1:1 hexanes-Et ${ }_{2} \mathrm{O}$ ); HRMS (ESI) $\mathrm{m} / z 460.9771$ (460.9752 calcd for $\mathrm{C}_{21} \mathrm{H}_{19} \mathrm{O}_{2} \mathrm{Br}_{2}[\mathrm{M}+\mathrm{H}]^{+}$).

(1d).<smiles>O=C(/C=C/CC/C=C/C(=O)c1ccc([N+](=O)[O-])cc1)c1ccc([N+](=O)[O-])cc1</smiles>

${ }^{1} \mathrm{H}$ NMR $\left(\mathrm{CDCl}_{3}, 500 \mathrm{MHz}\right) \delta 8.32(\mathrm{~d}, J=8.8 \mathrm{~Hz}, 4 \mathrm{H}), 8.06(\mathrm{~d}, J=8.8 \mathrm{~Hz}, 4 \mathrm{H}), 7.13(\mathrm{dt}, J=$ 15.4, $6.9 \mathrm{~Hz}, 2 \mathrm{H}), 6.91(\mathrm{~d}, J=15.4 \mathrm{~Hz}, 2 \mathrm{H}), 2.45$ (q, $J=6.9 \mathrm{~Hz}, 4 \mathrm{H}), 1.83$ (quintet, $J=7.5 \mathrm{~Hz}$, $2 \mathrm{H}) ;{ }^{13} \mathrm{C} \mathrm{NMR}\left(\mathrm{CDCl}_{3}, 125 \mathrm{MHz}\right) \delta 189.0,150.6,150.1,142.6,129.4,126.1,123.8,32.3,26.6$; IR (film, $\left.\mathrm{cm}^{-1}\right)$ 3109, 2934, 2856, 1671, 1617, 1601, 1524, 1344, 1213; TLC R $0.32(2: 1$ hexanes-EtOAc); HRMS (ESI) $m / z 395.1246$ (395.1243 calcd for $\mathrm{C}_{21} \mathrm{H}_{19} \mathrm{~N}_{2} \mathrm{O}_{6}[\mathrm{M}+\mathrm{H}]^{+}$). 
(9).<smiles>CC(=O)/C=C/CC/C=C/C(C)=O</smiles>

9

${ }^{1} \mathrm{H}$ NMR $\left(\mathrm{CDCl}_{3}, 400 \mathrm{MHz}\right) \delta 6.78(\mathrm{dt}, J=15.9,6.9 \mathrm{~Hz}, 2 \mathrm{H}), 6.10(\mathrm{~d}, J=16.0 \mathrm{~Hz}, 2 \mathrm{H}), 2.31-$ $2.24(\mathrm{~m}, 10 \mathrm{H}), 2.39$ (q, $J=7.1 \mathrm{~Hz}, 2 \mathrm{H}), 1.68$ (quintet, $J=7.4 \mathrm{~Hz}, 2 \mathrm{H}) ;{ }^{13} \mathrm{C} \mathrm{NMR}_{\left(\mathrm{CDCl}_{3}, 100\right.}$ MHz) $\delta$ 198.5, 147.0, 131.8, 31.8, 27.0, 26.4; IR (film, $\left.\mathrm{cm}^{-1}\right)$ 3001, 2933, 2856, 1697, 1673, 1620, 1427, 1359, 1254, 1182, 972; TLC $\mathrm{R}_{f} 0.29$ (2:1 hexanes-EtOAc); HRMS (ESI) $\mathrm{m} / \mathrm{z}$ 203.1054 (203.1048 calcd for $\left.\mathrm{C}_{11} \mathrm{H}_{16} \mathrm{O}_{2} \mathrm{Na}[\mathrm{M}+\mathrm{Na}]^{+}\right)$.

(13).<smiles>CCOC(=O)/C=C/CCC/C=C/C(=O)c1ccccc1</smiles>

13

${ }^{1} \mathrm{H} \mathrm{NMR}\left(\mathrm{CDCl}_{3}, 500 \mathrm{MHz}\right) \delta 7.93(\mathrm{~d}, J=7.0 \mathrm{~Hz}, 2 \mathrm{H}), 7.56(\mathrm{t}, J=7.3 \mathrm{~Hz}, 1 \mathrm{H}), 7.47$ (t, $J=7.6$ $\mathrm{Hz}, 2 \mathrm{H}), 7.07-6.89(\mathrm{~m}, 3 \mathrm{H}), 5.85(\mathrm{dt}, J=15.8,1.5 \mathrm{~Hz}, 1 \mathrm{H}), 4.19(\mathrm{q}, J=7.1 \mathrm{~Hz}, 2 \mathrm{H}), 2.36(\mathrm{q}, J=$ $6.9 \mathrm{~Hz}, 2 \mathrm{H}$ ), 2.28 (q, $J=6.9 \mathrm{~Hz}, 2 \mathrm{H}), 1.72$ (quintet, $J=7.3 \mathrm{~Hz}, 2 \mathrm{H}), 1.29(\mathrm{t}, J=7.1 \mathrm{~Hz}, 3 \mathrm{H}) ;{ }^{13} \mathrm{C}$ NMR $\left(\mathrm{CDCl}_{3}, 125 \mathrm{MHz}\right) \delta 191.0,166.9,148.9,148.4,138.2,133.1,128.9,128.9,126.8,122.4$, 60.6, 32.4, 31.9, 26.9, 14.6; IR (film, $\mathrm{cm}^{-1}$ ) 2980, 2936, 1715, 1672, 1652, 1616, 1442, 1264 , 1178; TLC $\mathrm{R}_{f} 0.28$ (3:1 hexanes-EtOAc); HRMS (ESI) $\mathrm{m} / z 295.1310$ (295.1310 calcd for $\left.\mathrm{C}_{17} \mathrm{H}_{20} \mathrm{O}_{3} \mathrm{Na}[\mathrm{M}+\mathrm{Na}]^{+}\right)$.

\section{General Procedure B: Catalytic Intramolecular Rauhut-Currier Reactions.}

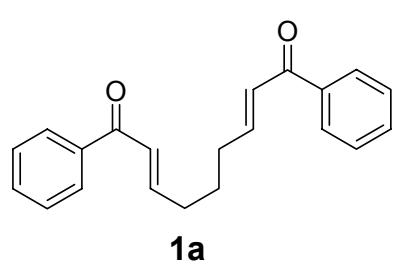

1a

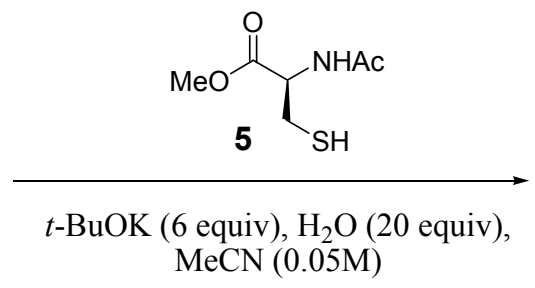

$\mathrm{MeCN}(0.05 \mathrm{M})$

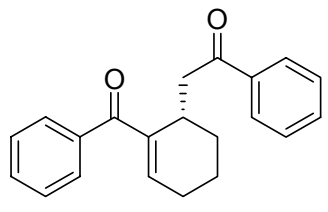

2a

Bisenone 1a (30.0 mg, $0.10 \mathrm{mmol})$ was dissolved in acetonitrile $(2.0 \mathrm{~mL})$ and water $(36 \mu \mathrm{L}, 2.0$ $\mathrm{mmol})$ and cooled to $-40{ }^{\circ} \mathrm{C}$. AcCysOMe (5) $(17.6 \mathrm{mg}, 0.10 \mathrm{mmol})$ and $t$-BuOK $(67.0 \mathrm{mg}, 0.59$ $\mathrm{mmol}$ ) were added sequentially and the reaction was allowed to stir for $24 \mathrm{~h}$ at $-40{ }^{\circ} \mathrm{C}$. The reaction mixture was then filtered through a short plug of silica (hexanes-EtOAc, 1:1), concentrated, and purified by flash chromatography (hexanes-EtOAc, 5:1) to afford 2a as a pale yellow oil (21 mg, $0.069 \mathrm{mmol}, 70 \%$ ). Compounds 2b-d, 10, 12, and 14 were prepared by analogous methodology. NOTE: In order to ensure high efficiency and enantioselectivity, the 
reaction concentration and equivalents of $t$-BuOK must be as described for each respective substrate. For runs employing less than $100 \mathrm{~mol} \%$ catalyst, reaction parameters other than catalyst loading remain constant.

(2a).<smiles>O=C(C[C@H]1CCCC=C1C(=O)c1ccccc1)c1ccccc1</smiles>

The characterization data for this compound matched that which has previously been reported. ${ }^{\text {ii }}$ $[\alpha]_{\mathrm{D}}-38.6$ ( $c$ 0.76, $\mathrm{CHCl}_{3}, 95 \%$ ee); Assay of enantiomeric purity: Enantiomers of product were separated by chiral HPLC employing a Chiralcel AD column (Daicel). Conditions: 96:4 hexanes-isopropanol; Flow rate $0.75 \mathrm{~mL} / \mathrm{min}$; $15.1 \mathrm{~min}$ (major ent), $20.5 \mathrm{~min}$ (minor ent).

(2b).<smiles>COc1ccc(C(=O)C[C@H]2CCCC=C2C(=O)c2ccc(OC)cc2)cc1</smiles>

General procedure B was followed, except that bisenone $\mathbf{1 b}(20.0 \mathrm{mg}, 0.055 \mathrm{mmol})$ was employed as starting material with $t$-BuOK $(43.2 \mathrm{mg}, 0.39 \mathrm{mmol})$ in acetonitrile $(5.5 \mathrm{~mL})$. Yield: 73\% (12.8 mg, $0.035 \mathrm{mmol}) ;{ }^{1} \mathrm{H} \mathrm{NMR}\left(\mathrm{CDCl}_{3}, 500 \mathrm{MHz}\right) \delta 8.05(\mathrm{~d}, J=8.9 \mathrm{~Hz}, 2 \mathrm{H}), 7.74$ $(\mathrm{d}, J=8.8 \mathrm{~Hz}, 2 \mathrm{H}), 6.96-9.92(\mathrm{~m}, 4 \mathrm{H}), 6.53(\mathrm{td}, J=3.9,1.1 \mathrm{~Hz}, 1 \mathrm{H}), 3.87(\mathrm{~s}, 3 \mathrm{H}), 3.85(\mathrm{~s}, 3 \mathrm{H})$, 3.47-3.45 (m, 1H), 3.34 (dd, $J=14.4,3.2 \mathrm{~Hz}, 1 \mathrm{H}), 2.69$ (dd, $J=14.4,10.8 \mathrm{~Hz}, 1 \mathrm{H}), 2.38-2.29$ $(\mathrm{m}, 1 \mathrm{H}), 2.23-2.15(\mathrm{~m}, 1 \mathrm{H}), 1.81-1.57(\mathrm{~m}, 4 \mathrm{H})$; ${ }^{13} \mathrm{C} \mathrm{NMR}\left(\mathrm{CDCl}_{3}, 125 \mathrm{MHz}\right) \delta 198.7,197.5$, 163.8, 163.2, 142.7, 142.0, 132.1, 131.6, 131.2, 130.3, 114.1, 113.8, 55.9, 55.8, 42.8, 31.6, 27.0, 26.4, 18.8; IR (film, $\mathrm{cm}^{-1}$ ) 2925, 2840, 1671, 1630, 1597, 1569, 1507, 1254, 1172, 1029; TLC R 0.36 (2:1 hexanes-EtOAc); $[\alpha]_{\mathrm{D}}+7.0$ (c $0.77, \mathrm{CHCl}_{3}, 90 \%$ ee); HRMS (ESI) $\mathrm{m} / z$ 365.1766 (365.1753 calcd for $\mathrm{C}_{23} \mathrm{H}_{25} \mathrm{O}_{4}[\mathrm{M}+\mathrm{H}]^{+}$); Assay of enantiomeric purity: Enantiomers of product were separated by chiral HPLC employing a Chiralcel AD column (Daicel). Conditions: 80:20 hexanes-isopropanol; Flow rate $0.75 \mathrm{~mL} / \mathrm{min}$; $19.3 \mathrm{~min}$ (major ent), $28.0 \mathrm{~min}$ (minor ent). 
(2c).<smiles>O=C(C[C@@H]1CCCC=C1C(=O)c1ccc(Br)cc1)c1ccc(Br)cc1</smiles>

General procedure B was followed, except that bisenone 1c $(30.0 \mathrm{mg}, 0.065 \mathrm{mmol})$ was employed as starting material with $t$-BuOK $(36.0 \mathrm{mg}, 0.33 \mathrm{mmol})$ in acetonitrile $(2.2 \mathrm{~mL})$. Yield: 70\% (21 mg, $0.045 \mathrm{mmol})$; ${ }^{1} \mathrm{H} \mathrm{NMR}\left(\mathrm{CDCl}_{3}, 500 \mathrm{MHz}\right) \delta 7.93(\mathrm{~d}, J=8.6 \mathrm{~Hz}, 2 \mathrm{H}), 7.62-$ $7.53(\mathrm{~m}, 6 \mathrm{H}), 6.62(\mathrm{t}, J=3.6 \mathrm{~Hz}, 1 \mathrm{H}), 3.43-3.41(\mathrm{~m}, 1 \mathrm{H}), 3.33(\mathrm{dd}, J=14.8,3.5 \mathrm{~Hz}, 1 \mathrm{H}), 2.80$ $(\mathrm{dd}, J=14.8,10.2 \mathrm{~Hz}, 1 \mathrm{H}), 2.38-2.31(\mathrm{~m}, 1 \mathrm{H}), 2.25-2.19(\mathrm{~m}, 1 \mathrm{H}), 1.79-1.61(\mathrm{~m}, 4 \mathrm{H})$; ${ }^{13} \mathrm{C}$ NMR $\left(\mathrm{CDCl}_{3}, 125 \mathrm{MHz}\right) \delta 198.9,197.2,145.8,141.6,137.8,135.8,132.3,131.8,131.2,130.4,128.6$, 126.9, 42.8, 30.7, 26.9, 26.5, 18.4; IR (film, cm ${ }^{-1}$ ) 2932, 2861, 1679, 1640, 1585, 1393, 1263, 1067, 1008; TLC R $\mathrm{R}_{f} 0.64$ (3:1 hexanes-EtOAc); $\left.\alpha\right]_{\mathrm{D}}+9.7$ (c 1.0, $\mathrm{CHCl}_{3}, 93 \%$ ee); HRMS (ESI) $\mathrm{m} / \mathrm{z} 460.9751$ (460.9752 calcd for $\mathrm{C}_{21} \mathrm{H}_{19} \mathrm{O}_{2} \mathrm{Br}_{2}[\mathrm{M}+\mathrm{H}]^{+}$); Assay of enantiomeric purity: Enantiomers of product were separated by chiral HPLC employing a Chiralcel AD column (Daicel). Conditions: 96:4 hexanes-isopropanol; Flow rate $0.75 \mathrm{~mL} / \mathrm{min} ; 26.3 \mathrm{~min}$ (major ent), 32.8 min (minor ent).

(2d).<smiles>O=C(C[C@@H]1CCCC=C1C(=O)c1ccc([N+](=O)[O-])cc1)c1ccc([N+](=O)[O-])cc1</smiles>

General procedure B was followed, except that bisenone 1d (20.0 $\mathrm{mg}, 0.051 \mathrm{mmol})$ was employed as starting material with $t$-BuOK $(11.4 \mathrm{mg}, 0.10 \mathrm{mmol})$ in acetonitrile $(5.1 \mathrm{~mL})$ and the reaction was allowed to stir for $4 \mathrm{~h}$. Yield: $71 \%(14.2 \mathrm{mg}, 0.036 \mathrm{mmol}) ;{ }^{1} \mathrm{H} \mathrm{NMR}\left(\mathrm{CDCl}_{3}\right.$, $400 \mathrm{MHz}) \delta 8.33(\mathrm{~d}, J=8.9 \mathrm{~Hz}, 2 \mathrm{H}), 8.30(\mathrm{~d}, J=8.8 \mathrm{~Hz}, 2 \mathrm{H}), 8.23(\mathrm{~d}, J=8.9 \mathrm{~Hz}, 2 \mathrm{H}), 7.78(\mathrm{~d}$, $J=8.8 \mathrm{~Hz}, 2 \mathrm{H}), 6.69(\mathrm{t}, J=3.6 \mathrm{~Hz}, 1 \mathrm{H}), 3.49-3.40(\mathrm{~m}, 2 \mathrm{H}), 2.99(\mathrm{dd}, J=15.0,9.4 \mathrm{~Hz}, 1 \mathrm{H})$,

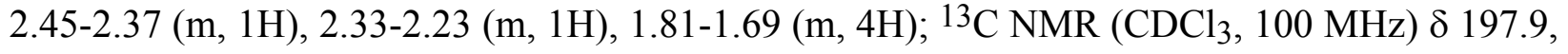
195.9, 150.3, 149.4, 148.1, 144.2, 141.1, 141.0, 129.9, 129.4, 123.9, 123.4, 42.8, 29.8, 26.5, 26.4, 17.8; IR (film, cm ${ }^{-1}$ ) 2937, 2864, 1689, 1643, 1599, 1522, 1345, 1265; TLC $\mathrm{R}_{f} 0.32$ (3:1 hexanes-EtOAc); $[\alpha]_{\mathrm{D}}+15.0$ (c 1.0, $\mathrm{CHCl}_{3}, 84 \%$ ee); HRMS (ESI) $\mathrm{m} / z$ 395.1259 (395.1243 calcd for $\mathrm{C}_{21} \mathrm{H}_{19} \mathrm{~N}_{2} \mathrm{O}_{6}[\mathrm{M}+\mathrm{H}]^{+}$); Assay of enantiomeric purity: Enantiomers of product were separated by chiral HPLC employing a Chiralcel AD column (Daicel). Conditions: 80:20 hexanes-isopropanol; Flow rate $0.75 \mathrm{~mL} / \mathrm{min}$; $42.9 \mathrm{~min}$ (major ent), $39.0 \mathrm{~min}$ (minor ent). 
(10).<smiles>CC(=O)CC1CCCC=C1C(C)=O</smiles>

10

General procedure B was followed, except that bisenone $9(20.0 \mathrm{mg}, 0.11 \mathrm{mmol})$ was employed as starting material with $t$-BuOK $(37.0 \mathrm{mg}, 0.33 \mathrm{mmol})$ in acetonitrile $(5.5 \mathrm{~mL})$ and the reaction was allowed to stir for $40 \mathrm{~h}$. Yield: $55 \%(7.2 \mathrm{mg}, 0.040 \mathrm{mmol}) ;{ }^{1} \mathrm{H} \mathrm{NMR}\left(\mathrm{CDCl}_{3}, 500 \mathrm{MHz}\right) \delta$ $6.95(\mathrm{t}, J=3.9 \mathrm{~Hz}, 1 \mathrm{H}), 3.20-3.15(\mathrm{~m}, 1 \mathrm{H}), 2.60(\mathrm{dd}, J=15.6,3.2 \mathrm{~Hz}, 1 \mathrm{H}), 2.31-2.26(\mathrm{~m}, 5 \mathrm{H})$, $2.17(\mathrm{~s}, 3 \mathrm{H}), 1.66-1.52(\mathrm{~m}, 5 \mathrm{H}) ;{ }^{13} \mathrm{C} \mathrm{NMR}\left(\mathrm{CDCl}_{3}, 125 \mathrm{MHz}\right) \delta ; 208.7,199.2,142.9,142.5$, 48.0, 30.1, 28.2, 26.6, 26.4, 25.9, 17.4; IR (film, $\mathrm{cm}^{-1}$ ) 2923, 2854, 1717, 1660, 1635, 1351, 1233, 1160; TLC R $\mathrm{R}_{f} 0.39$ (2:1 hexanes-EtOAc); $[\alpha]_{\mathrm{D}}-43$ (c $0.42, \mathrm{CHCl}_{3}, 90 \%$ ee); HRMS (ESI) $m / z 203.1056$ (203.1048 calcd for $\left.\mathrm{C}_{11} \mathrm{H}_{16} \mathrm{O}_{2} \mathrm{Na}[\mathrm{M}+\mathrm{Na}]^{+}\right)$; Assay of enantiomeric purity: Enantiomers of product were separated by chiral HPLC employing a Chiralcel AD column (Daicel). Conditions: 97:3 hexanes-isopropanol; Flow rate $0.60 \mathrm{~mL} / \mathrm{min} ; 14.9 \mathrm{~min}$ (major ent), 16.0 min (minor ent).

(12).<smiles>O=C(C[C@@H]1CCCC=C1C(=O)c1ccco1)c1ccco1</smiles>

12

General procedure B was followed, except that bisenone $11(30.0 \mathrm{mg}, 0.11 \mathrm{mmol})$ was employed as starting material with $t$-BuOK $(74.0 \mathrm{mg}, 0.66 \mathrm{mmol})$ in acetonitrile $(2.2 \mathrm{~mL})$ and the reaction was allowed to stir for $40 \mathrm{~h}$. Yield: $54 \%(13.7 \mathrm{mg}, 0.048 \mathrm{mmol}) ;{ }^{1} \mathrm{H} \mathrm{NMR}\left(\mathrm{CDCl}_{3}, 500 \mathrm{MHz}\right) \delta$ $7.62(\mathrm{dd}, J=1.7,0.7 \mathrm{~Hz}, 1 \mathrm{H}), 7.57$ (dd, $J=1.7,0.6 \mathrm{~Hz}, 1 \mathrm{H}), 7.41$ (d, $J=3.7 \mathrm{~Hz}, 1 \mathrm{H}), 7.11$ (dd, $J$ $=3.6,0.6 \mathrm{~Hz}, 1 \mathrm{H}), 7.00(\mathrm{td}, J=3.9,1.0 \mathrm{~Hz}, 1 \mathrm{H}), 6.53-6.51(\mathrm{~m}, 2 \mathrm{H}), 3.48-3.45(\mathrm{~m}, 1 \mathrm{H}), 3.11(\mathrm{dd}$, $J=14.6,3.2 \mathrm{~Hz}, 1 \mathrm{H}), 2.66(\mathrm{dd}, J=14.6,10.6 \mathrm{~Hz}, 1 \mathrm{H}), 2.39-2.21(\mathrm{~m}, 2 \mathrm{H}), 1.78-1.63(\mathrm{~m}, 4 \mathrm{H})$; ${ }^{13} \mathrm{C} \mathrm{NMR}\left(\mathrm{CDCl}_{3}, 125 \mathrm{MHz}\right) \delta 188.2,183.7,152.4,152.3,146.5,146.4,142.1,140.9,119.1$, 118.2, 112.1, 111.7, 42.3, 30.6, 26.3, 26.1, 18.0; IR (film, $\mathrm{cm}^{-1}$ ) 3130, 2934, 2860, 1673, 1628, 1564, 1463, 1390, 1285; TLC R 0.32 (2:1 hexanes-EtOAc); $[\alpha]_{\mathrm{D}}+14$ (c $0.88, \mathrm{CHCl}_{3}, 92 \%$ ee); HRMS (ESI) $m / z 285.1133$ (285.1127 calcd for $\left.\mathrm{C}_{17} \mathrm{H}_{17} \mathrm{O}_{4}[\mathrm{M}+\mathrm{H}]^{+}\right)$; Assay of enantiomeric purity: Enantiomers of product were separated by chiral HPLC employing a Chiralcel AD column (Daicel). Conditions: 80:20 hexanes-isopropanol; Flow rate $0.75 \mathrm{~mL} / \mathrm{min}$; $10.2 \mathrm{~min}$ (major ent), 14.0 min (minor ent). 
(14).<smiles>CCOC(=O)CC1CCCC=C1C(=O)c1ccccc1</smiles>

14

General procedure B was followed, except that bisenone $13(20.0 \mathrm{mg}, 0.073 \mathrm{mmol})$ was employed as starting material with $t$-BuOK $(49.4 \mathrm{mg}, 0.44 \mathrm{mmol})$ in acetonitrile $(1.5 \mathrm{~mL})$. Yield: $66 \%(13.4 \mathrm{mg}, 0.049 \mathrm{mmol}) ;{ }^{1} \mathrm{H} \mathrm{NMR}\left(\mathrm{CDCl}_{3}, 500 \mathrm{MHz}\right) \delta 7.67(\mathrm{~d}, J=6.9 \mathrm{~Hz}, 2 \mathrm{H})$, $7.51(\mathrm{t}, J=7.4 \mathrm{~Hz}, 1 \mathrm{H}), 7.42(\mathrm{t}, J=7.4 \mathrm{~Hz}, 2 \mathrm{H}), 6.54(\mathrm{t}, J=3.9 \mathrm{~Hz}, 1 \mathrm{H}), 4.09$ (q, $J=7.1 \mathrm{~Hz}$, 2H), 3.40-3.33 (m, 1H), 2.59 (dd, $J=14.9,4.4 \mathrm{~Hz}, 1 \mathrm{H}), 2.40(\mathrm{dd}, J=15.1,9.1 \mathrm{~Hz}, 1 \mathrm{H}), 2.35-$ $2.26(\mathrm{~m}, 1 \mathrm{H}), 2.23-2.14(\mathrm{~m}, 1 \mathrm{H}), 1.85-1.61(\mathrm{~m}, 4 \mathrm{H}), 1.22(\mathrm{t}, J=7.1 \mathrm{~Hz}, 3 \mathrm{H}) ;{ }^{13} \mathrm{C} \mathrm{NMR}\left(\mathrm{CDCl}_{3}\right.$, $125 \mathrm{MHz}) \delta 197.6,172.4,143.9,141.2,138.6,131.6,129.3,128.0,60.2,38.1,30.1,27.1,26.0$, 18.3, 14.2; IR (film, $\mathrm{cm}^{-1}$ ) 2927, 2851, 1728, 1641, 1593, 1443, 1368, 1265, 1249, 1173; TLC Rf 0.52 (3:1 hexanes-EtOAc); $[\alpha]_{\mathrm{D}}-62$ (c $0.5, \mathrm{CHCl}_{3}, 67 \%$ ee); HRMS (ESI) $\mathrm{m} / z 295.1320$ (295.1310 calcd for $\left.\mathrm{C}_{17} \mathrm{H}_{20} \mathrm{O}_{3} \mathrm{Na}[\mathrm{M}+\mathrm{Na}]^{+}\right)$; Assay of enantiomeric purity: Enantiomers of product were separated by chiral HPLC employing a Chiralcel AD column (Daicel). Conditions: 96:4 hexanes-isopropanol; Flow rate $0.75 \mathrm{~mL} / \mathrm{min} ; 11.7 \mathrm{~min}$ (major ent), $14.6 \mathrm{~min}$ (minor ent).<smiles>O=C(CC1CCC=CC1C(=O)c1ccccc1)c1ccccc1</smiles>

17

${ }^{1} \mathrm{H} \mathrm{NMR}\left(\mathrm{CDCl}_{3}, 500 \mathrm{MHz}\right) \delta 7.94(\mathrm{dd}, J=8.2,1.2 \mathrm{~Hz}, 2 \mathrm{H}), 7.78(\mathrm{dd}, J=8.2,1.1 \mathrm{~Hz}, 2 \mathrm{H})$, $7.54(\mathrm{t}, J=7.25 \mathrm{~Hz}, 1 \mathrm{H}), 7.51-7.42(\mathrm{~m}, 3 \mathrm{H}), 7.35(\mathrm{t}, 7.8 \mathrm{~Hz}, 2 \mathrm{H}), 5.96-5.92(\mathrm{~m}, 1 \mathrm{H}), 5.80-5.75$ (m, $1 \mathrm{H}), 4.43$ (bs, 1H), 3.06 (dd, $J=17.0,7.9 \mathrm{~Hz}, 1 \mathrm{H}), 2.95$ (dd, $J=17.3,6.0 \mathrm{~Hz}, 1 \mathrm{H}), 2.85-2.78$ (m, 1H), 2.20-2.07 (m, 3H), 1.80-1.72 (m, 1H); ${ }^{13} \mathrm{C}$ NMR $\left(\mathrm{CDCl}_{3}, 125 \mathrm{MHz}\right) \delta$ 201.3, 199.7, 137.2, 137.1, 133.1, 132.9, 129.9, 128.7, 128.5, 128.3, 127.9, 124.1, 45.8, 39.6, 31.9, 25.2, 23.6; IR (film, cm ${ }^{-1}$ ) 3060, 3025, 2922, 1682, 1595, 1578, 1446, 1372, 1323, 1283, 1211, 999; TLC R $f$ 0.52 (3:1 hexanes-EtOAc); $[\alpha]_{\mathrm{D}}+54.3$ (c $0.23, \mathrm{CHCl}_{3}, 84 \%$ ee); HRMS (ESI) $\mathrm{m} / z 305.1552$ (305.1542 calcd for $\mathrm{C}_{21} \mathrm{H}_{21} \mathrm{O}_{2}[\mathrm{M}+\mathrm{H}]^{+}$); Assay of enantiomeric purity: Enantiomers of product were separated by chiral HPLC employing a Chiralcel AD column (Daicel). Conditions: 96:4 hexanes-isopropanol; Flow rate $0.75 \mathrm{~mL} / \mathrm{min} ; 26.1 \mathrm{~min}$ (major ent), $27.9 \mathrm{~min}$ (minor ent). 


\section{General Procedure C: Preparation of Rauhut-Currier Catalysts.}<smiles>COC(=O)C(N)CS</smiles>
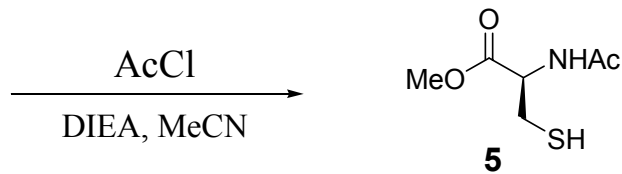

A white heterogeneous mixture of CysOMe $\mathrm{HCl}(1.00 \mathrm{~g}, 5.82 \mathrm{mmol})$ in acetonitrile $(58 \mathrm{~mL})$ was cooled to $0{ }^{\circ} \mathrm{C}$. N,N-Diisopropylethylamine $(935 \mu \mathrm{L}, 5.24 \mathrm{mmol})$ and acetyl chloride $(374 \mu \mathrm{L}$, $5.24 \mathrm{mmol})$ were added and the reaction was allowed to stir for 20 minutes. $\mathrm{NH}_{4} \mathrm{Cl}(50 \mathrm{~mL})$ was added at $0{ }^{\circ} \mathrm{C}$ and the reaction mixture was extracted with EtOAc $(2 \times 100 \mathrm{~mL})$. The combined organic layers were washed with saturated $\mathrm{NaHCO}_{3}(100 \mathrm{ml})$, and brine $(100 \mathrm{~mL})$, dried over $\mathrm{Na}_{2} \mathrm{SO}_{4}$, and concentrated. Flash chromatography of the crude material on silica gel (hexanesEtOAc, 1:2) yielded 5 as a white fluffy solid (422 mg, $2.38 \mathrm{mmol}, 41 \%) .{ }^{1} \mathrm{H} \mathrm{NMR}\left(\mathrm{CDCl}_{3}, 500\right.$ MHz) $\delta$ 6.41-6.33 (bs, 1H), $4.90(\mathrm{dt}, J=7.9,3.8 \mathrm{~Hz}, 1 \mathrm{H}), 3.80(\mathrm{~s}, 3 \mathrm{H}), 3.07-2.98(\mathrm{~m}, 2 \mathrm{H}), 2.08$ $(\mathrm{s}, 3 \mathrm{H}), 1.34(\mathrm{t}, J=8.9 \mathrm{~Hz}, 1 \mathrm{H}) ;{ }^{13} \mathrm{C} \mathrm{NMR}\left(\mathrm{CDCl}_{3}, 125 \mathrm{MHz}\right) \delta 171.0,170.1,53.9,53.2,27.2$, 23.5; IR (film, $\mathrm{cm}^{-1}$ ) 3276, 2952, 1748, 1652, 1532, 1437, 1369, 1213; TLC $\mathrm{R}_{f} 0.21$ (1:2 hexanes-EtOAc); $[\alpha]_{\mathrm{D}}+71$ (c 1.0, $\mathrm{CHCl}_{3}$ ); HRMS (ESI) $\mathrm{m} / z 200.0363$ (200.0357 calcd for $\mathrm{C}_{6} \mathrm{H}_{11} \mathrm{NO}_{3} \mathrm{SNa}[\mathrm{M}+\mathrm{Na}]^{+}$).<smiles>COC(=O)[C@H](CS)NC(=O)C(C)C</smiles>

General procedure $\mathrm{C}$ was followed, except that $\mathrm{CysOMe} \cdot \mathrm{HCl}(100 \mathrm{mg}, 0.58 \mathrm{mmol})$ was used with isobutyryl chloride $(55 \mu \mathrm{L}, 0.52 \mathrm{mmol})$ and $\mathrm{N}, \mathrm{N}$-diisopropylethylamine ( $94 \mu \mathrm{L}, 0.52 \mathrm{mmol})$ in acetonitrile $(5.8 \mathrm{~mL})$. Yield: $39 \%(47 \mathrm{mg}, 0.23 \mathrm{mmol}) ;{ }^{1} \mathrm{H} \mathrm{NMR}\left(\mathrm{CDCl}_{3}, 500 \mathrm{MHz}\right) \delta 6.40-$ $6.33(\mathrm{bs}, 1 \mathrm{H}), 4.89$ (dt, $J=7.7,3.7 \mathrm{~Hz}, 1 \mathrm{H}), 3.80(\mathrm{~s}, 3 \mathrm{H}), 3.03(\mathrm{dd}, J=8.8,4.1 \mathrm{~Hz}, 2 \mathrm{H}), 2.47$ (quintet, $J=6.9 \mathrm{~Hz}, 1 \mathrm{H}), 1.31(\mathrm{t}, J=8.9 \mathrm{~Hz}, 1 \mathrm{H}), 1.20(\mathrm{~d}, J=4.1 \mathrm{~Hz}, 3 \mathrm{H}), 1.19(\mathrm{~d}, J=4.1 \mathrm{~Hz}$, $3 \mathrm{H}) ;{ }^{13} \mathrm{C} \mathrm{NMR}\left(\mathrm{CDCl}_{3}, 125 \mathrm{MHz}\right) \delta 177.1,171.2,53.6,53.2,35.9,27.3,20.0$, 19.7; IR (film, $\left.\mathrm{cm}^{-1}\right) 3322,2962,2921,1749,1744,1650,1528,1430,1340,1319,1213$; TLC R 0.64 (1:2 hexanes-EtOAc); $[\alpha]_{\mathrm{D}}+59$ (c 1.0, $\mathrm{CHCl}_{3}$ ); HRMS (ESI) $\mathrm{m} / z 206.0858$ (206.0851 calcd for $\left.\mathrm{C}_{8} \mathrm{H}_{16} \mathrm{NO}_{3} \mathrm{~S}[\mathrm{M}+\mathrm{H}]^{+}\right)$.<smiles>COC(=O)[C@H](CS)NC(=O)C(C)(C)C</smiles>

General procedure $\mathrm{C}$ was followed, except that $\mathrm{CysOMe} \cdot \mathrm{HCl}(200 \mathrm{mg}, 1.2 \mathrm{mmol})$ was used with pivaloyl chloride $(123 \mu \mathrm{L}, 1.0 \mathrm{mmol})$ and $\mathrm{N}, \mathrm{N}$-diisopropylethylamine $(174 \mu \mathrm{L}, 1.0 \mathrm{mmol})$ in acetonitrile $(11.6 \mathrm{~mL})$. Yield: $42 \%(107 \mathrm{mg}, 0.49 \mathrm{mmol}) ;{ }^{1} \mathrm{H}$ NMR $\left(\mathrm{CDCl}_{3}, 500 \mathrm{MHz}\right) \delta 6.58-$ $6.48(\mathrm{bs}, 1 \mathrm{H}), 4.85(\mathrm{dt}, J=7.9,3.9 \mathrm{~Hz}, 1 \mathrm{H}), 3.80(\mathrm{~s}, 3 \mathrm{H}), 3.03(\mathrm{dd}, J=8.8,4.1 \mathrm{~Hz}, 2 \mathrm{H}), 1.29(\mathrm{t}$, 
$J=9.0 \mathrm{~Hz}, 1 \mathrm{H}), 1.25(\mathrm{~s}, 9 \mathrm{H}) ;{ }^{13} \mathrm{C} \mathrm{NMR}\left(\mathrm{CDCl}_{3}, 125 \mathrm{MHz}\right) \delta 178.7,171.3,53.7,53.2,39.2$, 27.8, 27.2; IR (film, $\mathrm{cm}^{-1}$ ) 3349, 2953, 1747, 1653, 1648, 1513, 1438, 1207; TLC R $\mathrm{R}_{f} 0.73$ (1:2 hexanes-EtOAc); $[\alpha]_{\mathrm{D}}+55$ (c 1.0, $\mathrm{CHCl}_{3}$ ); HRMS (ESI) $\mathrm{m} / z 220.1004$ (220.1007 calcd for $\left.\mathrm{C}_{9} \mathrm{H}_{18} \mathrm{NO}_{3} \mathrm{~S}[\mathrm{M}+\mathrm{H}]^{+}\right)$.

\section{Determination of Absolute Configuration.}
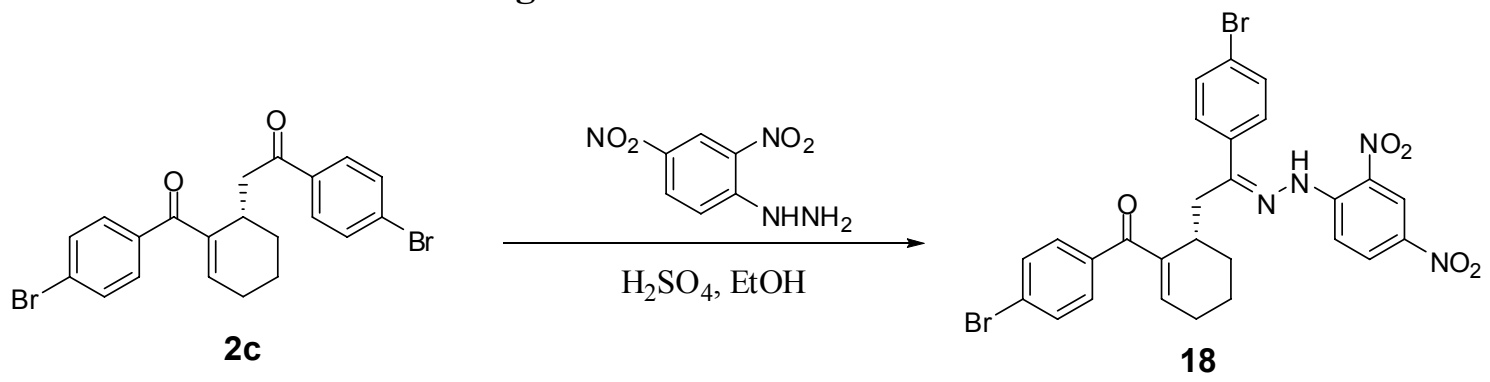

2,4-dinitrophenylhydrazine (5.4 mg, $0.022 \mathrm{mmol})$ and $0.5 \mathrm{~N} \mathrm{H}_{2} \mathrm{SO}_{4}(22 \mu \mathrm{L}, 0.011 \mathrm{mmol})$ were added to a solution of $2 \mathbf{c}(10 \mathrm{mg}, 0.022 \mathrm{mmol})$ in ethanol $(100 \mu \mathrm{L})$. The red heterogeneous mixture was heated to reflux for $12 \mathrm{~h}$, at which point excess 2,4-dinitrophenylhydrazine (10.8 $\mathrm{mg}, 0.044 \mathrm{mmol}$ ) was added and refluxed for an additional $12 \mathrm{~h}$ until starting material was consumed as indicated by TLC. The solid material was collected and purified by flash chromatography (hexanes-EtOAc, 10:1) to afford $\mathbf{1 8}$ as an orange solid $(6.3 \mathrm{mg}, 0.010 \mathrm{mmol}$, 45\%). X-ray quality crystals were prepared by recrystallizing 18 from an ether-ethyl acetate solution affording bright orange plate crystals. ${ }^{1} \mathrm{H} \mathrm{NMR}\left(\mathrm{CDCl}_{3}, 500 \mathrm{MHz}\right) \delta 11.6(\mathrm{~s}, 1 \mathrm{H}), 9.17$ $(\mathrm{d}, J=2.5 \mathrm{~Hz}, 1 \mathrm{H}), 8.36(\mathrm{dd}, J=9.6,2.5 \mathrm{~Hz}, 1 \mathrm{H}), 8.08(\mathrm{~d}, J=9.6 \mathrm{~Hz}, 1 \mathrm{H}), 7.87(\mathrm{~d}, J=8.6 \mathrm{~Hz}$, 2H), $7.59(\mathrm{~d}, J=8.6 \mathrm{~Hz}, 2 \mathrm{H}), 7.53(\mathrm{~d}, J=8.6 \mathrm{~Hz}, 2 \mathrm{H}), 7.42(\mathrm{~d}, J=8.6 \mathrm{~Hz}, 2 \mathrm{H}), 6.69(\mathrm{t}, J=3.8$ $\mathrm{Hz}, 1 \mathrm{H}), 3.39-3.30(\mathrm{~m}, 1 \mathrm{H}), 3.24(\mathrm{dd}, J=14.4,5.6 \mathrm{~Hz}, 1 \mathrm{H}), 2.79(\mathrm{dd}, J=14.4,9.6 \mathrm{~Hz}, 1 \mathrm{H})$,

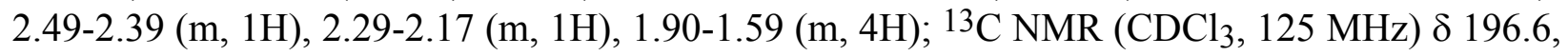
154.5, 146.9, 145.4, 140.6, 138.8, 137.1, 135.6, 132.3, 131.9, 131.0, 130.6, 130.2, 129.1, 127.2, 125.1, 123.8, 117.3, 31.5, 31.2, 27.3, 26.6, 18.5; IR (film, cm ${ }^{-1}$ ) 3317, 2927, 2856, 1645, 1617 , 1586, 1514, 1502, 1486, 1331, 1307, 1263; TLC R 0.53 (3:1 hexanes-EtOAc); $[\alpha]_{\mathrm{D}}+50(c 0.45$, $\mathrm{CHCl}_{3}$ ); HRMS (ESI) $m / z 641.0034\left(641.0035\right.$ calcd for $\left.\mathrm{C}_{27} \mathrm{H}_{23} \mathrm{Br}_{2} \mathrm{~N}_{4} \mathrm{O}_{5}[\mathrm{M}+\mathrm{H}]^{+}\right)$.

Crystallographic Data for Compound 18.

Data Collection - Performed and solved by Dr. Christopher Incarvito.

An orange plate crystal of $\mathrm{C}_{27} \mathrm{H}_{22} \mathrm{Br}_{2} \mathrm{~N}_{4} \mathrm{O}_{5}$ having approximate dimensions of $0.20 \times 0.20 \times 0.10$ $\mathrm{mm}^{3}$ was mounted with epoxy cement on the tip of a fine glass fiber. All measurements were made on a Nonius KappaCCD diffractometer with graphite monochromated Mo-K $\alpha$ radiation.

Cell constants and an orientation matrix for data collection corresponded to a primitive orthorhombic cell with dimensions:

$$
\begin{array}{ll}
a=7.3503(15) \AA & \alpha=90^{\circ} \\
b=11.878(2) \AA & \beta=90^{\circ}
\end{array}
$$




$$
\begin{aligned}
& \mathrm{c}=33.132(7) \AA \quad \gamma=90^{\circ} \\
& \mathrm{V}=2892.6(10) \AA^{3}
\end{aligned}
$$

For $\mathrm{Z}=4$ and F.W. $=642.31$, the calculated density is $1.475 \mathrm{~g} / \mathrm{cm}^{3}$. Based on a statistical analysis of intensity distribution, and the successful solution and refinement of the structure, the space group was determined to be $P 2_{1} 2_{1} 2_{1}(\# 19)$.

The data were collected at a temperature of $173(2) \mathrm{K}$ to a maximum $2 \theta$ value of $58.22^{\circ}$. Three omega scans consisting of 108, 108, and 87 data frames, respectively, were collected with a frame width of $0.7^{\circ}$ and a detector-to-crystal distance, Dx, of $43.0 \mathrm{~mm}$. Each frame was exposed twice (for the purpose of de-zingering) for a total of $21 \mathrm{~s}$. The data frames were processed and scaled using the DENZO software package. ${ }^{\text {iv }}$

\section{$\underline{\text { Data Reduction }}$}

A total of 7386 reflections were collected of which 7386 were unique and observed $\left(\mathrm{R}_{\text {int }}=0.000\right.$, Friedel pairs not mergerd). The linear absorption coefficient, $\mu$, for Mo-K $\alpha$ radiation is 28.44 $\mathrm{cm}^{-1}$, and no absorption correction was applied. The data were corrected for Lorentz and polarization effects.

\section{$\underline{\text { Structure Solution and Refinement }}$}

The structure was solved by direct methods and expanded using Fourier techniques. ${ }^{\mathrm{v}}$ The nonhydrogen atoms were refined anisotropically, and hydrogen atoms, with exceptions noted, were treated as idealized contributions. The final cycle of full-matrix least-squares refinement ${ }^{\mathrm{vi}}$ on $\mathrm{F}$ was based on 7386 observed reflections (I > 2.00\%(I)) and 347 variable parameters and converged with unweighted and weighted agreement factors of:

$$
\begin{gathered}
\mathrm{R}=\Sigma\|\mathrm{Fo}|-| \mathrm{Fc}\| / \Sigma|\mathrm{Fo}|=0.0521 \\
\mathrm{R}_{\mathrm{W}}=\left\{\Sigma\left[\mathrm{w}\left(\mathrm{F}_{\mathrm{o}}^{2}-\mathrm{F}_{\mathrm{c}}{ }^{2}\right)^{2}\right] / \Sigma\left[\mathrm{w}\left(\mathrm{F}_{\mathrm{o}}\right)^{2}\right]\right\}^{1 / 2}=0.1252
\end{gathered}
$$

The maximum and minimum peaks on the final difference Fourier map corresponded to 0.990 and $-0.442 \mathrm{e}^{-} / \AA^{3}$ respectively.

\section{$\underline{\text { Structural Description }}$}

The compound crystallized in the chiral orthorhombic space group $P 2{ }_{1} 2_{1} 2_{1}$ with one molecule in the asymmetric unit and four molecules in the unit cell.

$\mathrm{H}(2)$ was located from the residual electron difference map and freely refined with isotropic displacement parameters. No geometric restraints were applied to the $\mathrm{N}(2)-\mathrm{H}(2)$ bond, which refined to a distance of 0.76(5) $\AA$. As illustrated in Figure 3, $\mathrm{H}(2)$ is hydrogen bonded to $\mathrm{O}(2)$ of the adjacent nitro-group. Interatomic distances are $2.03 \AA$ for $\mathrm{H}(2) \cdots \mathrm{O}(2)$ and $2.60 \AA$ for $\mathrm{N}(2) \cdots \mathrm{O}(2)$. The $\mathrm{N}(2)-\mathrm{H}(2) \cdots \mathrm{O}$ angle is $131.3^{\circ}$. 
Extensive $\pi$-stacking is present in the crystal lattice. As illustrated in Figures 4 and 5, the $\pi$ stacking is present between the dinitro-substituted phenyl ring, $\mathrm{C}(22-27)$ and one of the bromosubstituted phenyl rings, $C(16-21)$. Interplane separations are approximately $3.6 \AA$ and the stacking propagates along the crystallographic a-axis.

The absolute molecular configuration was unambiguously determined [Flack $=-0.013(10)$ ] ORTEPs, packing diagrams and full crystallographic tables follow.

Table 1. Crystal data and structure refinement.

\begin{tabular}{|c|c|c|}
\hline Empirical formula & \multicolumn{2}{|l|}{$\mathrm{C}_{27} \mathrm{H}_{22} \mathrm{Br}_{2} \mathrm{~N}_{4} \mathrm{O}_{5}$} \\
\hline Formula weight & \multicolumn{2}{|l|}{642.31} \\
\hline Temperature & \multicolumn{2}{|l|}{$173(2) \mathrm{K}$} \\
\hline Wavelength & \multicolumn{2}{|l|}{$0.71073 \AA$} \\
\hline Crystal system & \multicolumn{2}{|l|}{ Orthorhombic } \\
\hline Space group & \multicolumn{2}{|l|}{$\mathrm{P} 2(1) 2(1) 2(1)$} \\
\hline \multirow[t]{3}{*}{ Unit cell dimensions } & $\mathrm{a}=7.3503(15) \AA$ & $\alpha=90^{\circ}$. \\
\hline & $\mathrm{b}=11.878(2) \AA$ & $\beta=90^{\circ}$. \\
\hline & $\mathrm{c}=33.132(7) \AA$ & $\gamma=90^{\circ}$. \\
\hline Volume & \multicolumn{2}{|l|}{$2892.6(10) \AA^{3}$} \\
\hline Z & \multicolumn{2}{|l|}{4} \\
\hline Density (calculated) & \multicolumn{2}{|l|}{$1.475 \mathrm{~g} / \mathrm{cm}^{3}$} \\
\hline Absorption coefficient & \multicolumn{2}{|l|}{$28.44 \mathrm{~cm}^{-1}$} \\
\hline $\mathrm{F}(000)$ & \multicolumn{2}{|l|}{1288} \\
\hline Crystal size & \multicolumn{2}{|c|}{$0.20 \times 0.20 \times 0.10 \mathrm{~mm}^{3}$} \\
\hline Theta range for data collection & \multicolumn{2}{|l|}{2.84 to $29.11^{\circ}$. } \\
\hline Index ranges & \multicolumn{2}{|c|}{$-10<=\mathrm{h}<=10,-16<=\mathrm{k}<=16,-44<=\mathrm{l}<=45$} \\
\hline Reflections collected & \multicolumn{2}{|l|}{7386} \\
\hline Independent reflections & \multicolumn{2}{|c|}{$7386[\mathrm{R}(\mathrm{int})=0.0000]$} \\
\hline Completeness to theta $=29.11^{\circ}$ & \multicolumn{2}{|l|}{$98.9 \%$} \\
\hline Absorption correction & \multicolumn{2}{|l|}{ None } \\
\hline Max. and min. transmission & \multicolumn{2}{|l|}{0.7641 and 0.6001} \\
\hline Refinement method & \multicolumn{2}{|c|}{ Full-matrix least-squares on $\mathrm{F}^{2}$} \\
\hline Data / restraints / parameters & \multicolumn{2}{|l|}{$7386 / 0$ / 347} \\
\hline Goodness-of-fit on $\mathrm{F}^{2}$ & \multicolumn{2}{|l|}{1.008} \\
\hline Final $\mathrm{R}$ indices $[\mathrm{I}>2 \operatorname{sigma}(\mathrm{I})]$ & \multicolumn{2}{|c|}{$\mathrm{R} 1=0.0521, \mathrm{wR} 2=0.1252$} \\
\hline $\mathrm{R}$ indices (all data) & \multicolumn{2}{|c|}{$\mathrm{R} 1=0.0891, \mathrm{wR} 2=0.1417$} \\
\hline
\end{tabular}


Absolute structure parameter

Largest diff. peak and hole
$-0.013(10)$

0.990 and -0.442 e. $\AA^{-3}$

Table 2. Atomic coordinates $\left(\mathrm{x} 10^{4}\right)$ and equivalent isotropic displacement parameters $\left(\AA^{2} \times 10^{3}\right)$ for miller_ca01. $\mathrm{U}(\mathrm{eq})$ is defined as one third of the trace of the orthogonalized $\mathrm{U}^{\mathrm{ij}}$ tensor.

\begin{tabular}{|c|c|c|c|c|}
\hline & $\mathrm{x}$ & $\mathrm{y}$ & $\mathrm{z}$ & $\mathrm{U}(\mathrm{eq})$ \\
\hline $\operatorname{Br}(1)$ & $8864(1)$ & $7359(1)$ & $4467(1)$ & $48(1)$ \\
\hline $\operatorname{Br}(2)$ & $8544(1)$ & $9560(1)$ & $8834(1)$ & $45(1)$ \\
\hline $\mathrm{O}(1)$ & $8632(5)$ & $8496(2)$ & $6489(1)$ & $35(1)$ \\
\hline $\mathrm{O}(2)$ & $6852(5)$ & $13348(3)$ & $6016(1)$ & $43(1)$ \\
\hline $\mathrm{O}(3)$ & $6366(6)$ & $14939(3)$ & $5730(1)$ & $51(1)$ \\
\hline $\mathrm{O}(4)$ & $5269(5)$ & $18273(3)$ & $7107(1)$ & $41(1)$ \\
\hline $\mathrm{O}(5)$ & $4519(5)$ & $18139(3)$ & $6476(1)$ & $43(1)$ \\
\hline $\mathrm{N}(1)$ & $7735(5)$ & $12705(3)$ & $7152(1)$ & $25(1)$ \\
\hline $\mathrm{N}(2)$ & $7469(5)$ & $13253(3)$ & $6786(1)$ & $27(1)$ \\
\hline $\mathrm{N}(3)$ & $6577(5)$ & $14366(3)$ & $6033(1)$ & $34(1)$ \\
\hline $\mathrm{N}(4)$ & $5157(5)$ & 17751(3) & $6790(1)$ & $31(1)$ \\
\hline $\mathrm{C}(1)$ & $9217(6)$ & $9414(4)$ & $5471(1)$ & $33(1)$ \\
\hline $\mathrm{C}(2)$ & $9104(7)$ & $9028(4)$ & $5076(1)$ & $41(1)$ \\
\hline $\mathrm{C}(3)$ & $8932(7)$ & $7886(4)$ & $5006(1)$ & $36(1)$ \\
\hline$C(4)$ & $8799(7)$ & $7122(4)$ & $5316(1)$ & $36(1)$ \\
\hline$C(5)$ & $8912(6)$ & $7516(4)$ & $5710(1)$ & $29(1)$ \\
\hline$C(6)$ & $9196(6)$ & $8653(3)$ & $5790(1)$ & $25(1)$ \\
\hline$C(7)$ & $9431(5)$ & $9019(3)$ & $6222(1)$ & $26(1)$ \\
\hline $\mathrm{C}(8)$ & $10658(6)$ & $9946(3)$ & $6327(1)$ & $25(1)$ \\
\hline $\mathrm{C}(9)$ & $12158(6)$ & $10147(4)$ & $6107(1)$ & $30(1)$ \\
\hline$C(10)$ & $13724(7)$ & $10880(4)$ & $6227(2)$ & $42(1)$ \\
\hline $\mathrm{C}(11)$ & $13630(6)$ & $11154(4)$ & $6676(2)$ & $36(1)$ \\
\hline$C(12)$ & $11688(5)$ & $11489(4)$ & $6788(1)$ & $29(1)$ \\
\hline$C(13)$ & $10377(5)$ & $10513(4)$ & $6731(1)$ & $24(1)$ \\
\hline$C(14)$ & $8394(6)$ & $10936(3)$ & $6768(1)$ & $25(1)$ \\
\hline$C(15)$ & $8133(5)$ & $11655(3)$ & $7142(1)$ & $24(1)$ \\
\hline$C(16)$ & $8366(5)$ & $11131(3)$ & $7545(1)$ & $24(1)$ \\
\hline$C(17)$ & $8016(6)$ & $9992(3)$ & $7603(1)$ & $30(1)$ \\
\hline
\end{tabular}




\begin{tabular}{lllll}
$\mathrm{C}(18)$ & $8097(6)$ & $9535(4)$ & $7982(2)$ & $35(1)$ \\
$\mathrm{C}(19)$ & $8511(6)$ & $10187(4)$ & $8307(1)$ & $30(1)$ \\
$\mathrm{C}(20)$ & $8901(6)$ & $11328(4)$ & $8260(1)$ & $31(1)$ \\
$\mathrm{C}(21)$ & $8825(6)$ & $11791(3)$ & $7877(1)$ & $28(1)$ \\
$\mathrm{C}(22)$ & $6924(5)$ & $14348(3)$ & $6788(1)$ & $22(1)$ \\
$\mathrm{C}(23)$ & $6490(6)$ & $14924(3)$ & $6423(1)$ & $27(1)$ \\
$\mathrm{C}(24)$ & $5916(6)$ & $16034(3)$ & $6422(1)$ & $27(1)$ \\
$\mathrm{C}(25)$ & $5797(5)$ & $16587(3)$ & $6785(1)$ & $26(1)$ \\
$\mathrm{C}(26)$ & $6232(7)$ & $16069(3)$ & $7147(1)$ & $28(1)$ \\
$\mathrm{C}(27)$ & $6772(6)$ & $14956(3)$ & $7149(1)$ & $26(1)$ \\
& & & & \\
\hline
\end{tabular}

Table 3. Bond lengths $[\AA]$ and angles $\left[{ }^{\circ}\right]$.

\begin{tabular}{|c|c|c|c|}
\hline $\operatorname{Br}(1)-C(3)$ & $1.895(4)$ & $C(9)-C(10)$ & $1.497(6)$ \\
\hline $\operatorname{Br}(2)-C(19)$ & $1.900(4)$ & $C(10)-C(11)$ & $1.524(7)$ \\
\hline $\mathrm{O}(1)-\mathrm{C}(7)$ & $1.230(5)$ & $C(11)-C(12)$ & $1.528(6)$ \\
\hline $\mathrm{O}(2)-\mathrm{N}(3)$ & $1.228(5)$ & $\mathrm{C}(12)-\mathrm{C}(13)$ & $1.520(6)$ \\
\hline $\mathrm{O}(3)-\mathrm{N}(3)$ & $1.223(5)$ & $C(13)-C(14)$ & $1.546(6)$ \\
\hline $\mathrm{O}(4)-\mathrm{N}(4)$ & $1.225(5)$ & $\mathrm{C}(14)-\mathrm{C}(15)$ & $1.516(6)$ \\
\hline $\mathrm{O}(5)-\mathrm{N}(4)$ & $1.230(5)$ & $C(15)-C(16)$ & $1.482(6)$ \\
\hline $\mathrm{N}(1)-\mathrm{C}(15)$ & $1.282(5)$ & $C(16)-C(17)$ & $1.391(6)$ \\
\hline $\mathrm{N}(1)-\mathrm{N}(2)$ & $1.388(5)$ & $\mathrm{C}(16)-\mathrm{C}(21)$ & $1.393(6)$ \\
\hline $\mathrm{N}(2)-\mathrm{H}(2)$ & $0.76(5)$ & $C(17)-C(18)$ & $1.367(6)$ \\
\hline $\mathrm{N}(2)-\mathrm{C}(22)$ & $1.361(5)$ & $\mathrm{C}(18)-\mathrm{C}(19)$ & $1.360(7)$ \\
\hline $\mathrm{N}(3)-\mathrm{C}(23)$ & $1.452(5)$ & $C(19)-C(20)$ & $1.394(6)$ \\
\hline N(4)-C(25) & $1.460(5)$ & $\mathrm{C}(20)-\mathrm{C}(21)$ & $1.383(6)$ \\
\hline $\mathrm{C}(1)-\mathrm{C}(2)$ & $1.389(6)$ & $C(22)-C(27)$ & $1.402(6)$ \\
\hline$C(1)-C(6)$ & $1.391(6)$ & $\mathrm{C}(22)-\mathrm{C}(23)$ & $1.426(6)$ \\
\hline$C(2)-C(3)$ & $1.382(7)$ & $C(23)-C(24)$ & $1.385(6)$ \\
\hline$C(3)-C(4)$ & $1.372(7)$ & $C(24)-C(25)$ & $1.372(6)$ \\
\hline$C(4)-C(5)$ & $1.390(6)$ & $C(25)-C(26)$ & $1.386(6)$ \\
\hline$C(5)-C(6)$ & $1.392(6)$ & $C(26)-C(27)$ & $1.381(6)$ \\
\hline$C(6)-C(7)$ & $1.507(6)$ & & \\
\hline$C(7)-C(8)$ & $1.465(6)$ & $\mathrm{C}(15)-\mathrm{N}(1)-\mathrm{N}(2)$ & $117.8(4)$ \\
\hline $\mathrm{C}(8)-\mathrm{C}(9)$ & $1.344(6)$ & $\mathrm{H}(2)-\mathrm{N}(2)-\mathrm{C}(22)$ & $119(4)$ \\
\hline $\mathrm{C}(8)-\mathrm{C}(13)$ & $1.513(6)$ & $\mathrm{H}(2)-\mathrm{N}(2)-\mathrm{N}(1)$ & $121(4)$ \\
\hline
\end{tabular}




\begin{tabular}{|c|c|}
\hline $\mathrm{C}(22)-\mathrm{N}(2)-\mathrm{N}(1)$ & $119.0(4)$ \\
\hline $\mathrm{O}(3)-\mathrm{N}(3)-\mathrm{O}(2)$ & $122.0(4)$ \\
\hline $\mathrm{O}(3)-\mathrm{N}(3)-\mathrm{C}(23)$ & $118.1(4)$ \\
\hline $\mathrm{O}(2)-\mathrm{N}(3)-\mathrm{C}(23)$ & $119.8(4)$ \\
\hline $\mathrm{O}(4)-\mathrm{N}(4)-\mathrm{O}(5)$ & $124.2(4)$ \\
\hline $\mathrm{O}(4)-\mathrm{N}(4)-\mathrm{C}(25)$ & $117.9(4)$ \\
\hline $\mathrm{O}(5)-\mathrm{N}(4)-\mathrm{C}(25)$ & $117.9(4)$ \\
\hline$C(2)-C(1)-C(6)$ & $120.1(4)$ \\
\hline$C(3)-C(2)-C(1)$ & $119.1(5)$ \\
\hline $\mathrm{C}(4)-\mathrm{C}(3)-\mathrm{C}(2)$ & $122.0(4)$ \\
\hline $\mathrm{C}(4)-\mathrm{C}(3)-\mathrm{Br}(1)$ & $119.0(3)$ \\
\hline $\mathrm{C}(2)-\mathrm{C}(3)-\mathrm{Br}(1)$ & $118.9(4)$ \\
\hline$C(3)-C(4)-C(5)$ & $118.4(4)$ \\
\hline$C(4)-C(5)-C(6)$ & $120.9(4)$ \\
\hline$C(5)-C(6)-C(1)$ & $119.2(4)$ \\
\hline$C(5)-C(6)-C(7)$ & $118.5(4)$ \\
\hline$C(1)-C(6)-C(7)$ & $122.2(4)$ \\
\hline $\mathrm{O}(1)-\mathrm{C}(7)-\mathrm{C}(8)$ & $120.2(4)$ \\
\hline $\mathrm{O}(1)-\mathrm{C}(7)-\mathrm{C}(6)$ & $118.8(4)$ \\
\hline$C(8)-C(7)-C(6)$ & $120.9(4)$ \\
\hline $\mathrm{C}(9)-\mathrm{C}(8)-\mathrm{C}(7)$ & $120.7(4)$ \\
\hline $\mathrm{C}(9)-\mathrm{C}(8)-\mathrm{C}(13)$ & $120.9(4)$ \\
\hline $\mathrm{C}(7)-\mathrm{C}(8)-\mathrm{C}(13)$ & $117.4(4)$ \\
\hline $\mathrm{C}(8)-\mathrm{C}(9)-\mathrm{C}(10)$ & $126.2(4)$ \\
\hline $\mathrm{C}(9)-\mathrm{C}(10)-\mathrm{C}(11)$ & $110.4(4)$ \\
\hline$C(10)-C(11)-C(12)$ & $109.7(4)$ \\
\hline$C(13)-C(12)-C(11)$ & $111.3(3)$ \\
\hline$C(8)-C(13)-C(12)$ & $111.3(3)$ \\
\hline$C(8)-C(13)-C(14)$ & $110.1(3)$ \\
\hline$C(12)-C(13)-C(14)$ & $109.9(3)$ \\
\hline$C(15)-C(14)-C(13)$ & $111.5(3)$ \\
\hline $\mathrm{N}(1)-\mathrm{C}(15)-\mathrm{C}(16)$ & $114.3(4)$ \\
\hline $\mathrm{N}(1)-\mathrm{C}(15)-\mathrm{C}(14)$ & $126.7(4)$ \\
\hline$C(16)-C(15)-C(14)$ & $118.9(3)$ \\
\hline$C(17)-C(16)-C(21)$ & $118.8(4)$ \\
\hline$C(17)-C(16)-C(15)$ & $120.9(4)$ \\
\hline
\end{tabular}

$\begin{array}{ll}\mathrm{C}(21)-\mathrm{C}(16)-\mathrm{C}(15) & 120.2(4) \\ \mathrm{C}(18)-\mathrm{C}(17)-\mathrm{C}(16) & 120.4(4) \\ \mathrm{C}(19)-\mathrm{C}(18)-\mathrm{C}(17) & 120.7(4) \\ \mathrm{C}(18)-\mathrm{C}(19)-\mathrm{C}(20) & 120.7(4) \\ \mathrm{C}(18)-\mathrm{C}(19)-\mathrm{Br}(2) & 120.5(3) \\ \mathrm{C}(20)-\mathrm{C}(19)-\mathrm{Br}(2) & 118.8(3) \\ \mathrm{C}(21)-\mathrm{C}(20)-\mathrm{C}(19) & 118.7(4) \\ \mathrm{C}(20)-\mathrm{C}(21)-\mathrm{C}(16) & 120.7(4) \\ \mathrm{N}(2)-\mathrm{C}(22)-\mathrm{C}(27) & 121.3(4) \\ \mathrm{N}(2)-\mathrm{C}(22)-\mathrm{C}(23) & 121.4(4) \\ \mathrm{C}(27)-\mathrm{C}(22)-\mathrm{C}(23) & 117.3(4) \\ \mathrm{C}(24)-\mathrm{C}(23)-\mathrm{C}(22) & 121.8(4) \\ \mathrm{C}(24)-\mathrm{C}(23)-\mathrm{N}(3) & 116.4(4) \\ \mathrm{C}(22)-\mathrm{C}(23)-\mathrm{N}(3) & 121.7(4) \\ \mathrm{C}(25)-\mathrm{C}(24)-\mathrm{C}(23) & 118.2(4) \\ \mathrm{C}(24)-\mathrm{C}(25)-\mathrm{C}(26) & 122.1(4) \\ \mathrm{C}(24)-\mathrm{C}(25)-\mathrm{N}(4) & 118.9(4) \\ \mathrm{C}(26)-\mathrm{C}(25)-\mathrm{N}(4) & 119.0(4) \\ \mathrm{C}(27)-\mathrm{C}(26)-\mathrm{C}(25) & 119.8(4) \\ \mathrm{C}(26)-\mathrm{C}(27)-\mathrm{C}(22) & 120.8(4) \\ & \end{array}$


Symmetry transformations used to generate equivalent atoms:

Table 4. Anisotropic displacement parameters $\left(\AA^{2} \times 10^{3}\right)$. The anisotropic displacement factor exponent takes the form: $-2 \pi^{2}\left[h^{2} a^{* 2} U^{11}+\ldots+2 h k a^{*} b^{*} U^{12}\right]$

\begin{tabular}{|c|c|c|c|c|c|c|}
\hline & $\mathrm{U}^{11}$ & $\mathrm{U}^{22}$ & $\mathrm{U}^{33}$ & $U^{23}$ & $\mathrm{U}^{13}$ & $\mathrm{U}^{12}$ \\
\hline $\operatorname{Br}(1)$ & $48(1)$ & $67(1)$ & $31(1)$ & $-16(1)$ & $5(1)$ & $-21(1)$ \\
\hline $\operatorname{Br}(2)$ & $52(1)$ & $47(1)$ & $35(1)$ & $13(1)$ & $0(1)$ & $7(1)$ \\
\hline $\mathrm{O}(1)$ & $49(2)$ & $28(2)$ & $29(2)$ & $0(1)$ & $7(2)$ & $-6(2)$ \\
\hline $\mathrm{O}(2)$ & $68(3)$ & $29(2)$ & $33(2)$ & $-4(1)$ & $-2(2)$ & $6(2)$ \\
\hline $\mathrm{O}(3)$ & $86(3)$ & $41(2)$ & $25(2)$ & $3(1)$ & $-1(2)$ & $14(2)$ \\
\hline $\mathrm{O}(4)$ & $55(2)$ & $24(2)$ & $45(2)$ & $-9(2)$ & $1(2)$ & $3(2)$ \\
\hline $\mathrm{O}(5)$ & $55(2)$ & $28(2)$ & $45(2)$ & $5(2)$ & $-10(2)$ & $12(2)$ \\
\hline $\mathrm{N}(1)$ & $29(2)$ & $20(2)$ & $27(2)$ & $2(2)$ & $-2(1)$ & $2(2)$ \\
\hline $\mathrm{N}(2)$ & $38(2)$ & $21(2)$ & $22(2)$ & $-1(2)$ & $2(2)$ & $2(2)$ \\
\hline $\mathrm{N}(3)$ & $38(2)$ & $37(2)$ & $26(2)$ & $2(2)$ & $1(2)$ & $5(2)$ \\
\hline $\mathrm{N}(4)$ & $32(2)$ & $20(2)$ & $42(2)$ & $-1(2)$ & $3(2)$ & $-1(2)$ \\
\hline$C(1)$ & $43(2)$ & $25(2)$ & $30(2)$ & $-3(2)$ & $-3(2)$ & $-2(2)$ \\
\hline$C(2)$ & $49(3)$ & $45(3)$ & $30(2)$ & $2(2)$ & $0(2)$ & $-6(2)$ \\
\hline$C(3)$ & $38(3)$ & 41(3) & $29(2)$ & $-12(2)$ & $2(2)$ & $-7(2)$ \\
\hline$C(4)$ & $41(3)$ & $32(2)$ & $36(2)$ & $-10(2)$ & $-1(2)$ & $-10(2)$ \\
\hline $\mathrm{C}(5)$ & $25(2)$ & $27(2)$ & $34(2)$ & $-5(2)$ & $3(2)$ & $-4(2)$ \\
\hline$C(6)$ & $27(2)$ & $25(2)$ & $23(2)$ & $-6(2)$ & $-1(2)$ & $-2(2)$ \\
\hline $\mathrm{C}(7)$ & $26(2)$ & $22(2)$ & $31(2)$ & $-2(2)$ & $3(2)$ & $2(2)$ \\
\hline$C(8)$ & $27(2)$ & $20(2)$ & $27(2)$ & $2(2)$ & $-1(2)$ & $4(2)$ \\
\hline $\mathrm{C}(9)$ & $30(2)$ & $25(2)$ & $34(3)$ & $-4(2)$ & $6(2)$ & $-4(2)$ \\
\hline$C(10)$ & $32(2)$ & $48(3)$ & $45(3)$ & $-14(2)$ & $10(2)$ & $-9(2)$ \\
\hline $\mathrm{C}(11)$ & $24(2)$ & $43(3)$ & $43(3)$ & $-9(2)$ & $0(2)$ & $-3(2)$ \\
\hline$C(12)$ & $22(2)$ & $29(2)$ & $37(2)$ & $-6(2)$ & $0(2)$ & $3(2)$ \\
\hline$C(13)$ & $24(2)$ & $23(2)$ & $26(2)$ & $-3(2)$ & $-1(2)$ & $4(2)$ \\
\hline$C(14)$ & $26(2)$ & $22(2)$ & $26(2)$ & $-6(2)$ & $-3(2)$ & $2(2)$ \\
\hline$C(15)$ & $19(2)$ & $26(2)$ & $29(2)$ & $1(2)$ & $0(2)$ & $-4(2)$ \\
\hline$C(16)$ & $19(2)$ & $22(2)$ & $31(2)$ & $-3(2)$ & $-2(2)$ & $3(2)$ \\
\hline$C(17)$ & $32(2)$ & $20(2)$ & $39(3)$ & $-2(2)$ & $-4(2)$ & $1(2)$ \\
\hline$C(18)$ & $38(2)$ & $22(2)$ & $45(3)$ & $4(2)$ & $0(2)$ & $5(2)$ \\
\hline
\end{tabular}




\begin{tabular}{lllllll}
$\mathrm{C}(19)$ & $27(2)$ & $34(2)$ & $29(2)$ & $7(2)$ & $-2(2)$ & $8(2)$ \\
$\mathrm{C}(20)$ & $34(2)$ & $30(2)$ & $30(2)$ & $-3(2)$ & $0(2)$ & $0(2)$ \\
$\mathrm{C}(21)$ & $30(2)$ & $22(2)$ & $31(2)$ & $-1(2)$ & $-3(2)$ & $-1(2)$ \\
$\mathrm{C}(22)$ & $22(2)$ & $21(2)$ & $24(2)$ & $2(2)$ & $1(2)$ & $-1(2)$ \\
$\mathrm{C}(23)$ & $29(2)$ & $26(2)$ & $27(2)$ & $-2(2)$ & $3(2)$ & $-3(2)$ \\
$\mathrm{C}(24)$ & $30(2)$ & $25(2)$ & $25(2)$ & $4(2)$ & $2(2)$ & $1(2)$ \\
$\mathrm{C}(25)$ & $21(2)$ & $24(2)$ & $32(2)$ & $1(2)$ & $0(2)$ & $2(2)$ \\
$\mathrm{C}(26)$ & $34(2)$ & $24(2)$ & $26(2)$ & $-3(2)$ & $2(2)$ & $-3(2)$ \\
$\mathrm{C}(27)$ & $34(2)$ & $23(2)$ & $21(2)$ & $1(2)$ & $-3(2)$ & $3(2)$ \\
\hline
\end{tabular}

Table 5. Hydrogen coordinates ( $\left.\times 10^{4}\right)$ and isotropic displacement parameters $\left(\AA^{2} \times 10^{3}\right)$.

\begin{tabular}{|c|c|c|c|c|}
\hline & $\mathrm{x}$ & $\mathrm{y}$ & $\mathrm{z}$ & $\mathrm{U}(\mathrm{eq})$ \\
\hline $\mathrm{H}(2)$ & $7640(70)$ & $12960(40)$ & $6587(15)$ & $30(14)$ \\
\hline $\mathrm{H}(1 \mathrm{~A})$ & 9309 & 10198 & 5523 & 39 \\
\hline $\mathrm{H}(2 \mathrm{~A})$ & 9146 & 9542 & 4857 & 50 \\
\hline $\mathrm{H}(4 \mathrm{~A})$ & 8633 & 6344 & 5262 & 44 \\
\hline $\mathrm{H}(5 \mathrm{~A})$ & 8794 & 7001 & 5928 & 35 \\
\hline $\mathrm{H}(9 \mathrm{~A})$ & 12230 & 9791 & 5851 & 36 \\
\hline $\mathrm{H}(10 \mathrm{~A})$ & 13693 & 11587 & 6068 & 50 \\
\hline $\mathrm{H}(10 \mathrm{~B})$ & 14882 & 10489 & 6167 & 50 \\
\hline $\mathrm{H}(11 \mathrm{~A})$ & 14474 & 11779 & 6739 & 44 \\
\hline $\mathrm{H}(11 \mathrm{~B})$ & 14004 & 10488 & 6835 & 44 \\
\hline $\mathrm{H}(12 \mathrm{~A})$ & 11658 & 11737 & 7074 & 35 \\
\hline $\mathrm{H}(12 \mathrm{~B})$ & 11298 & 12130 & 6618 & 35 \\
\hline $\mathrm{H}(13 \mathrm{~A})$ & 10603 & 9948 & 6949 & 29 \\
\hline $\mathrm{H}(14 \mathrm{~A})$ & 8077 & 11382 & 6526 & 30 \\
\hline $\mathrm{H}(14 \mathrm{~B})$ & 7562 & 10281 & 6781 & 30 \\
\hline $\mathrm{H}(17 \mathrm{~A})$ & 7720 & 9528 & 7379 & 36 \\
\hline $\mathrm{H}(18 \mathrm{~A})$ & 7861 & 8756 & 8018 & 42 \\
\hline $\mathrm{H}(20 \mathrm{~A})$ & 9213 & 11779 & 8486 & 37 \\
\hline $\mathrm{H}(21 \mathrm{~A})$ & 9088 & 12567 & 7840 & 33 \\
\hline $\mathrm{H}(24 \mathrm{~A})$ & 5613 & 16403 & 6177 & 32 \\
\hline $\mathrm{H}(26 \mathrm{~A})$ & 6159 & 16479 & 7392 & 34 \\
\hline
\end{tabular}




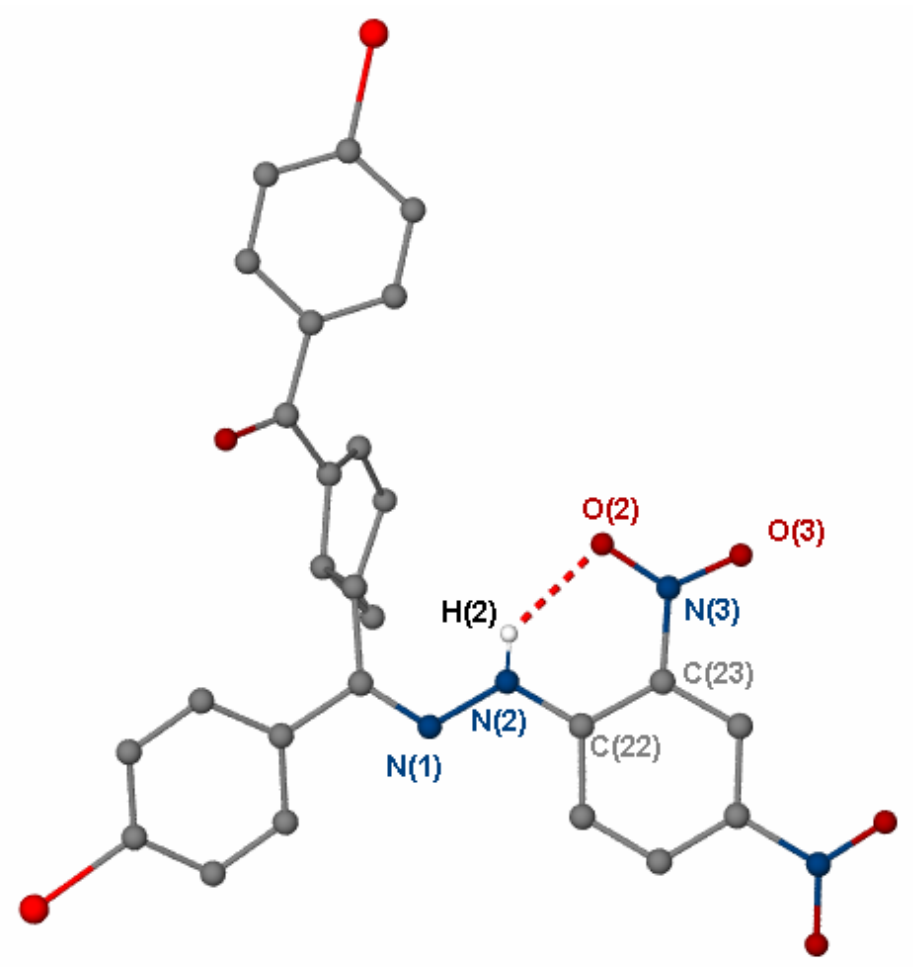

Figure 1. X-ray crystal structure for compound $\mathbf{1 8 .}$ 

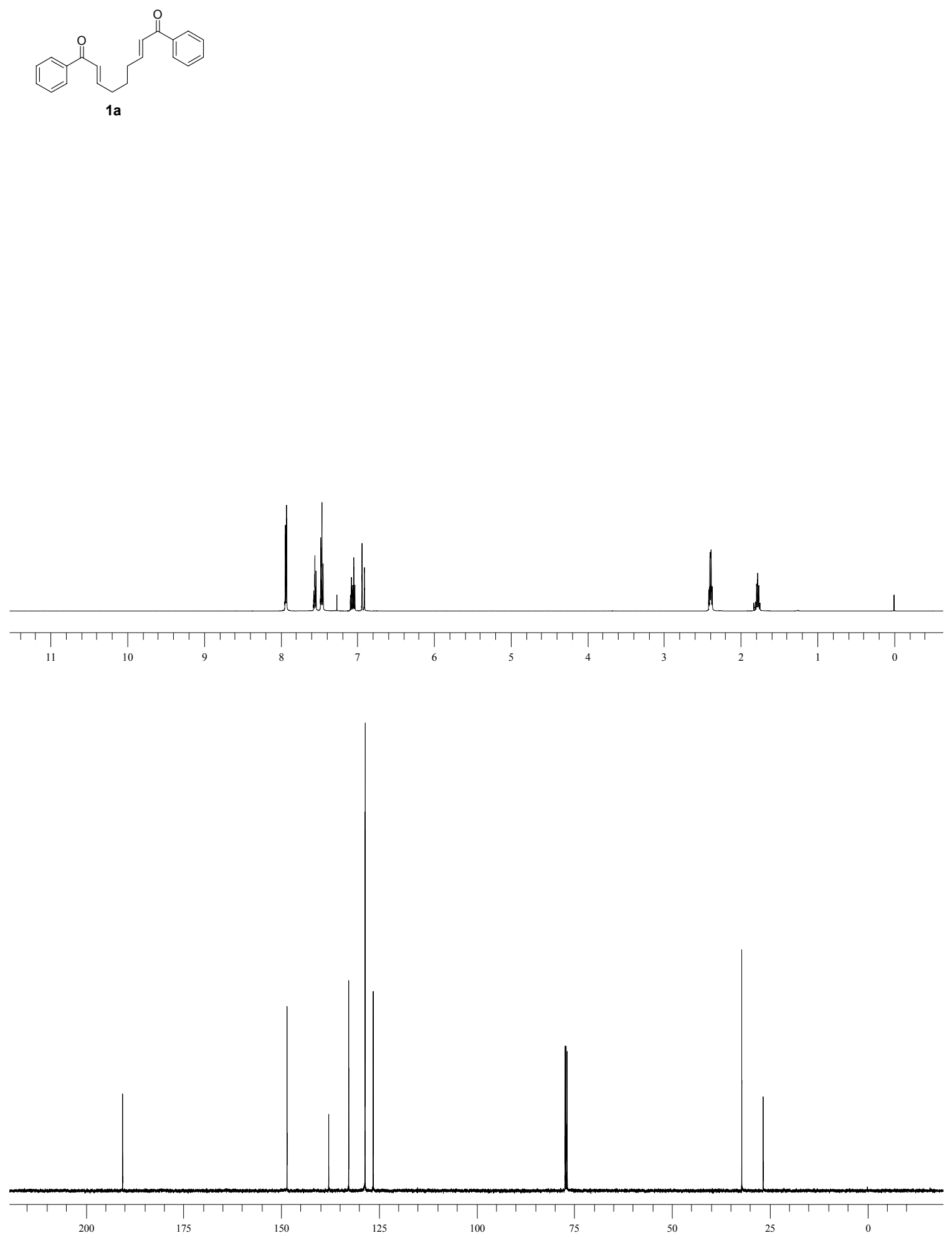

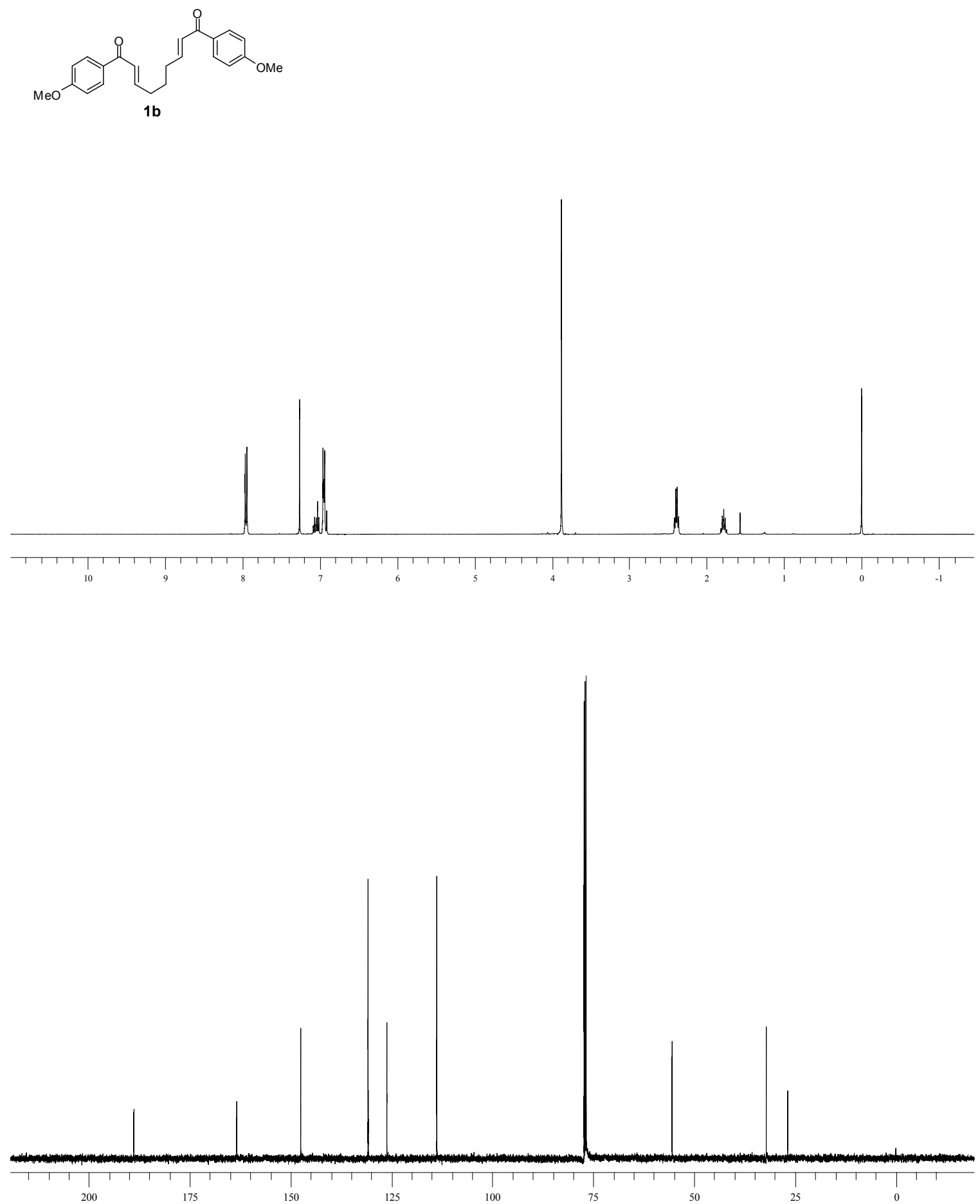
<smiles>CC(CC=CC(=O)c1ccc(Br)cc1)CCC=CC(=O)c1ccc(Br)cc1</smiles>

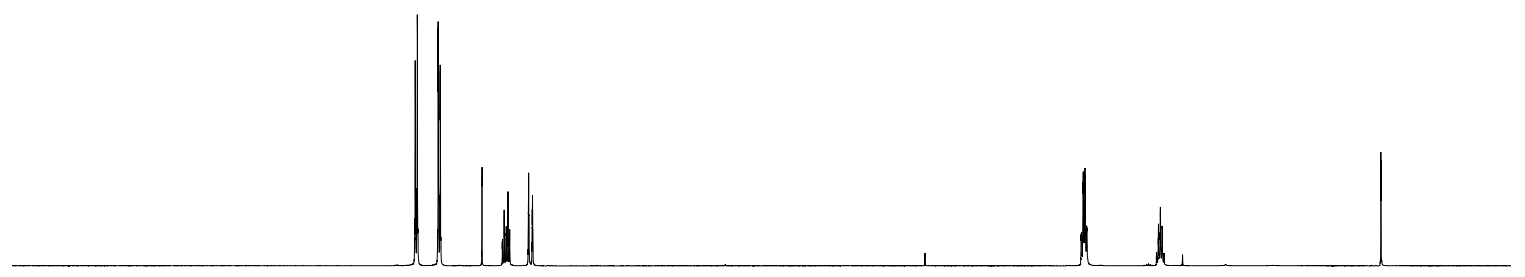

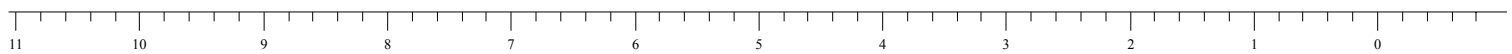

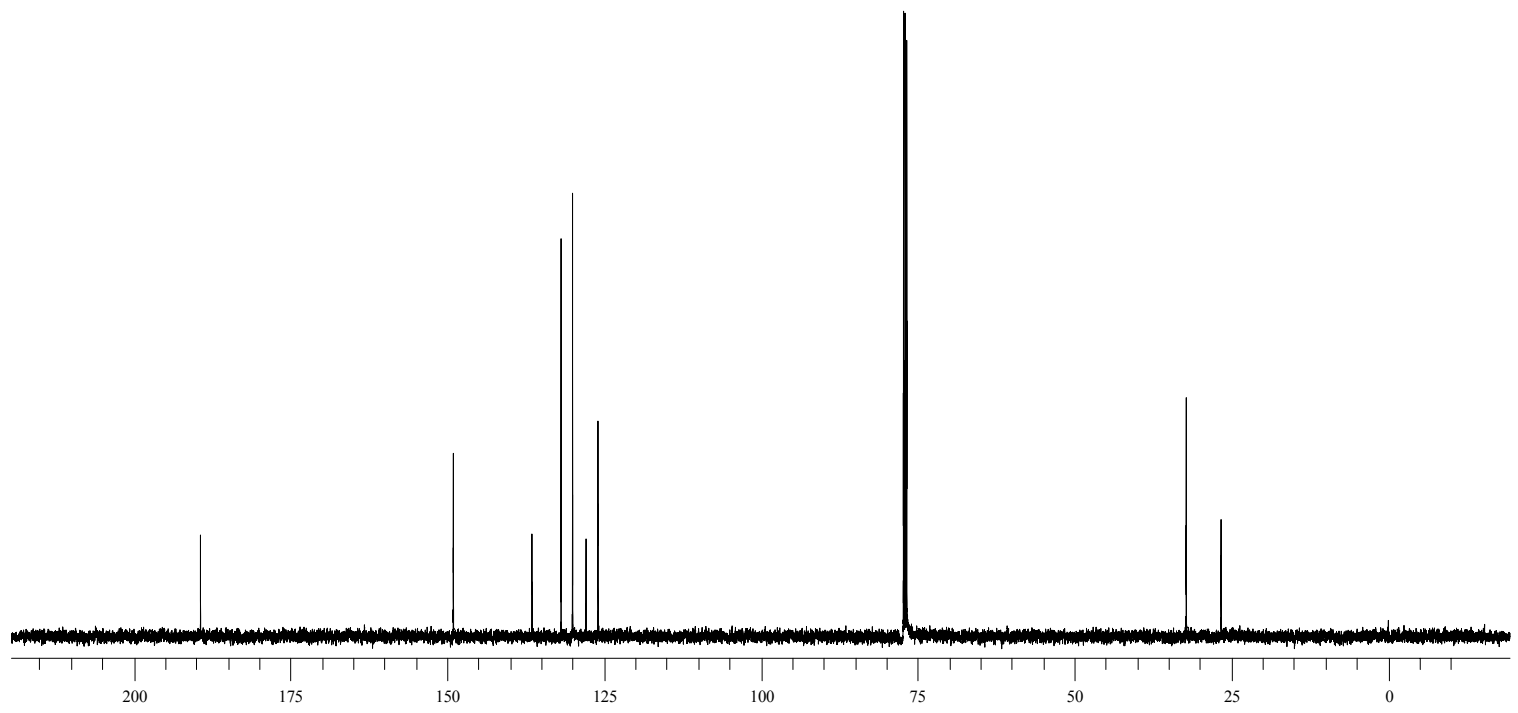


1d
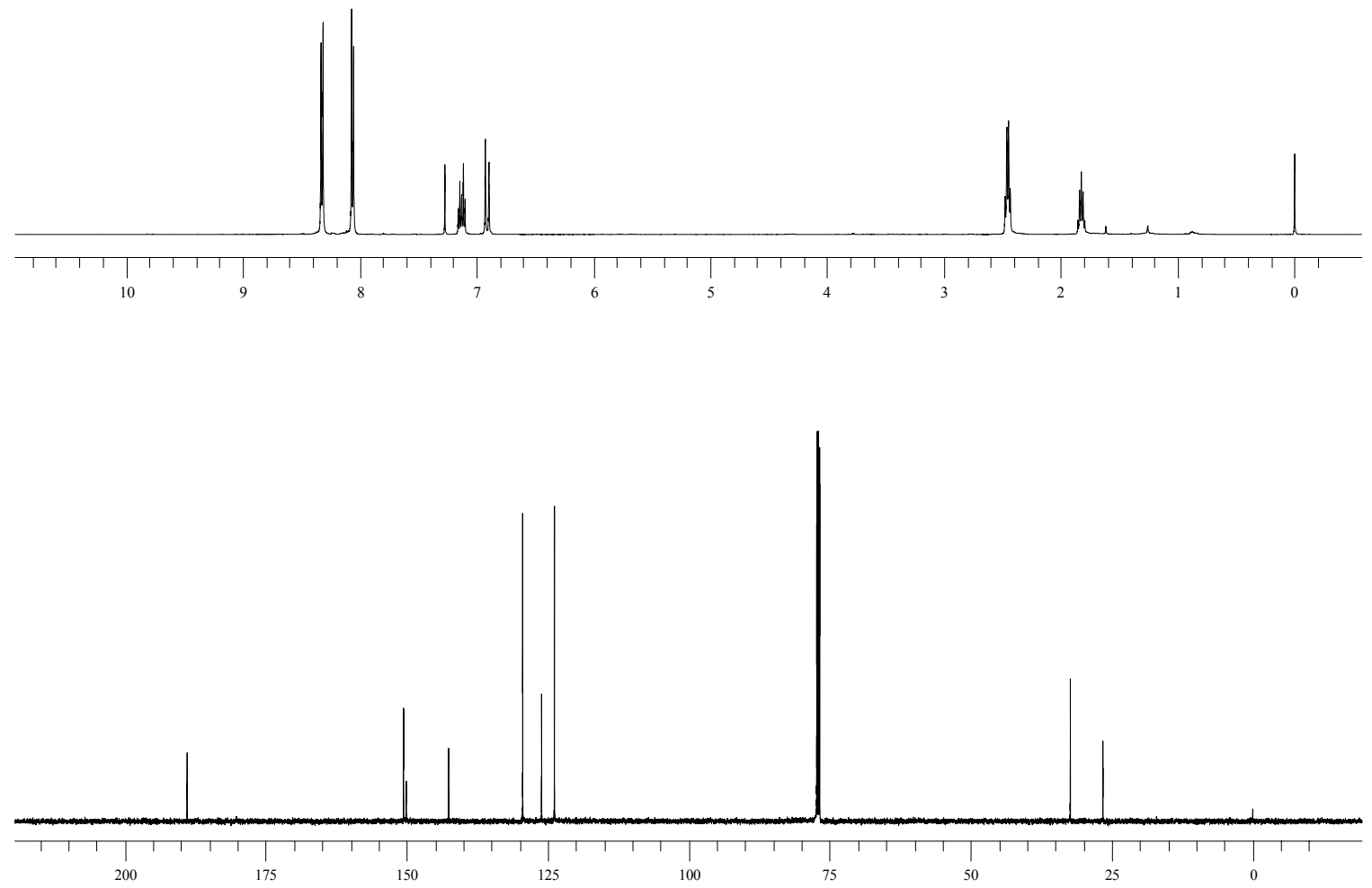

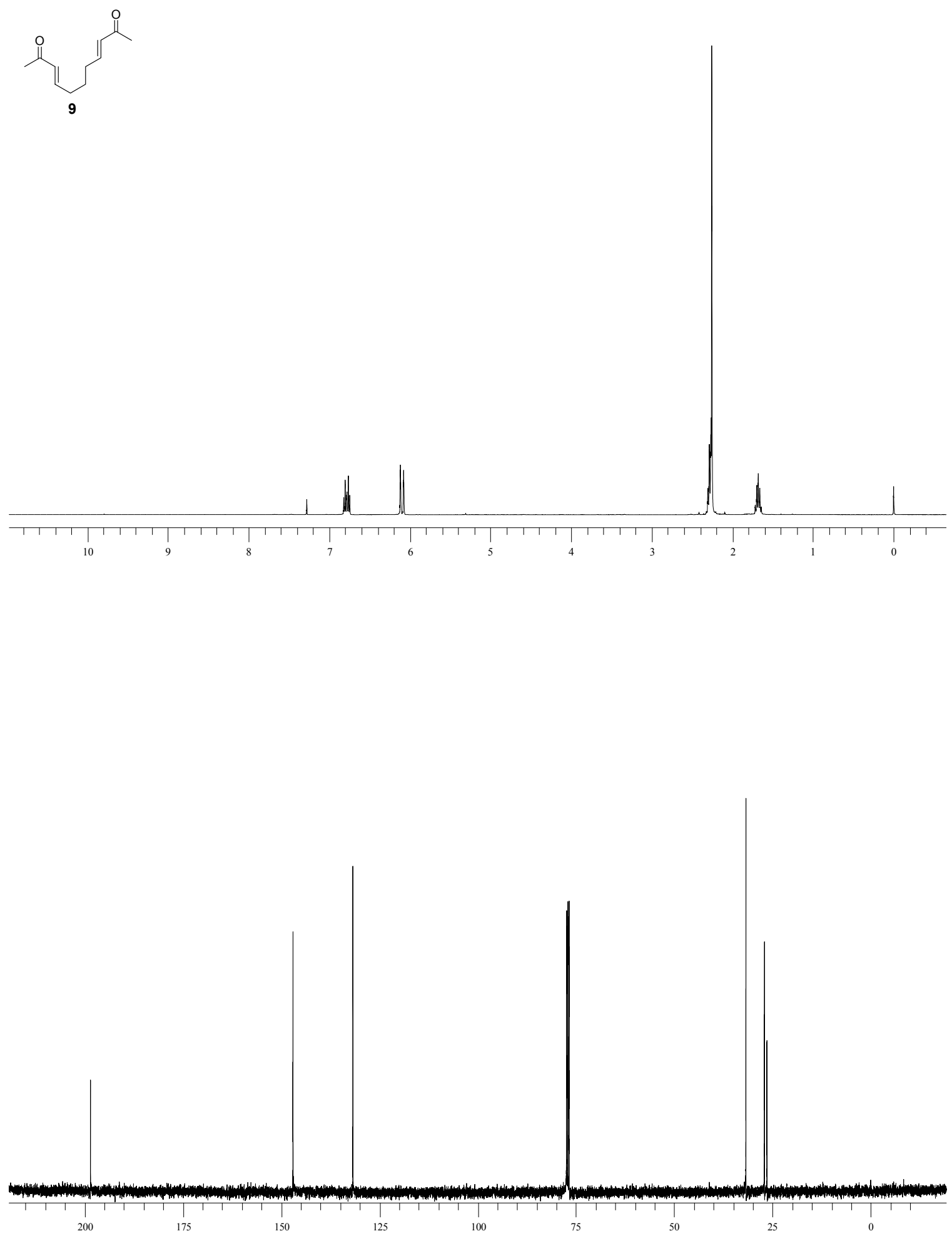


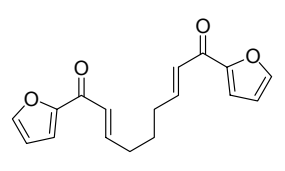

11
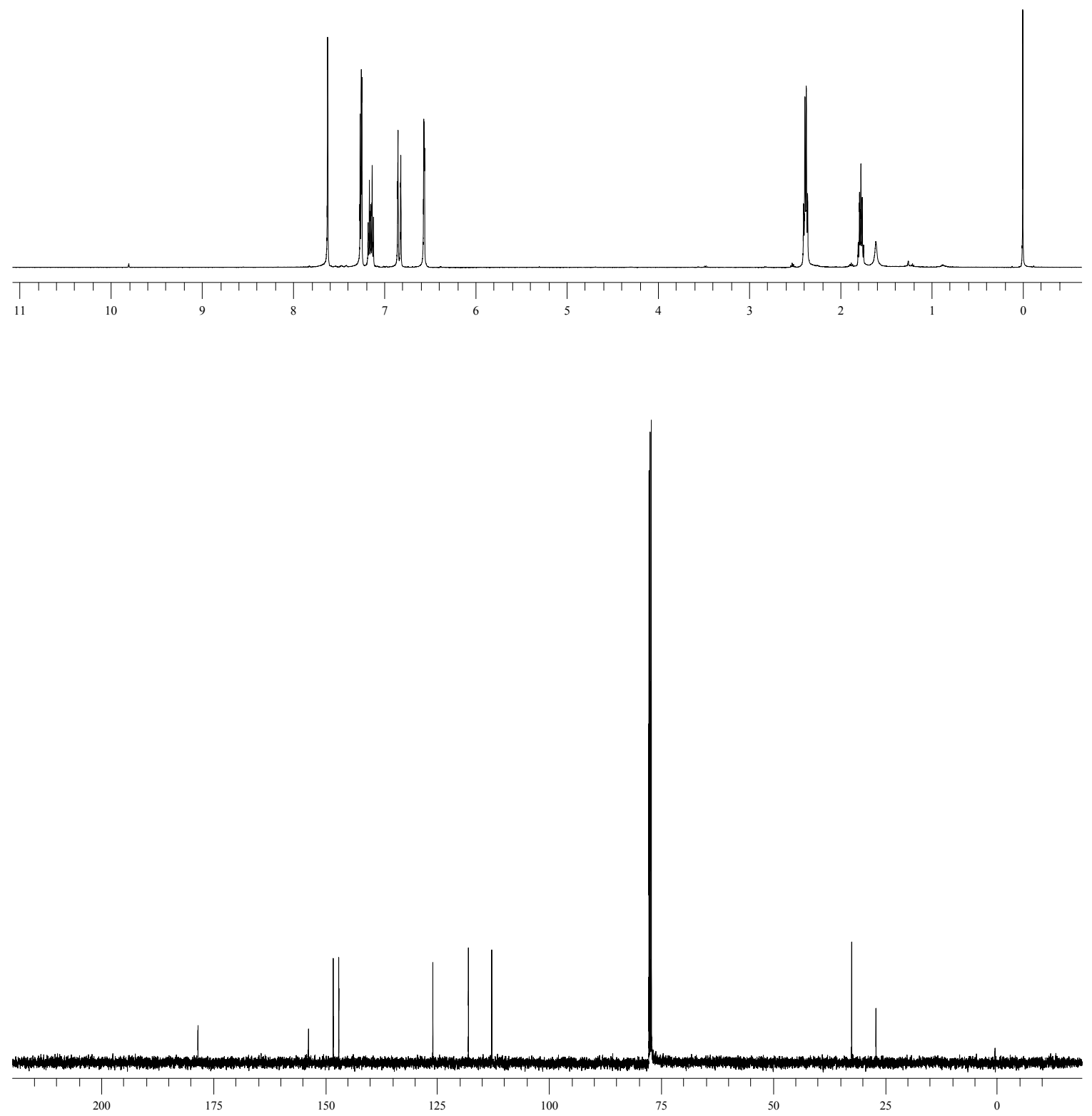


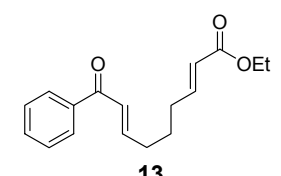

13
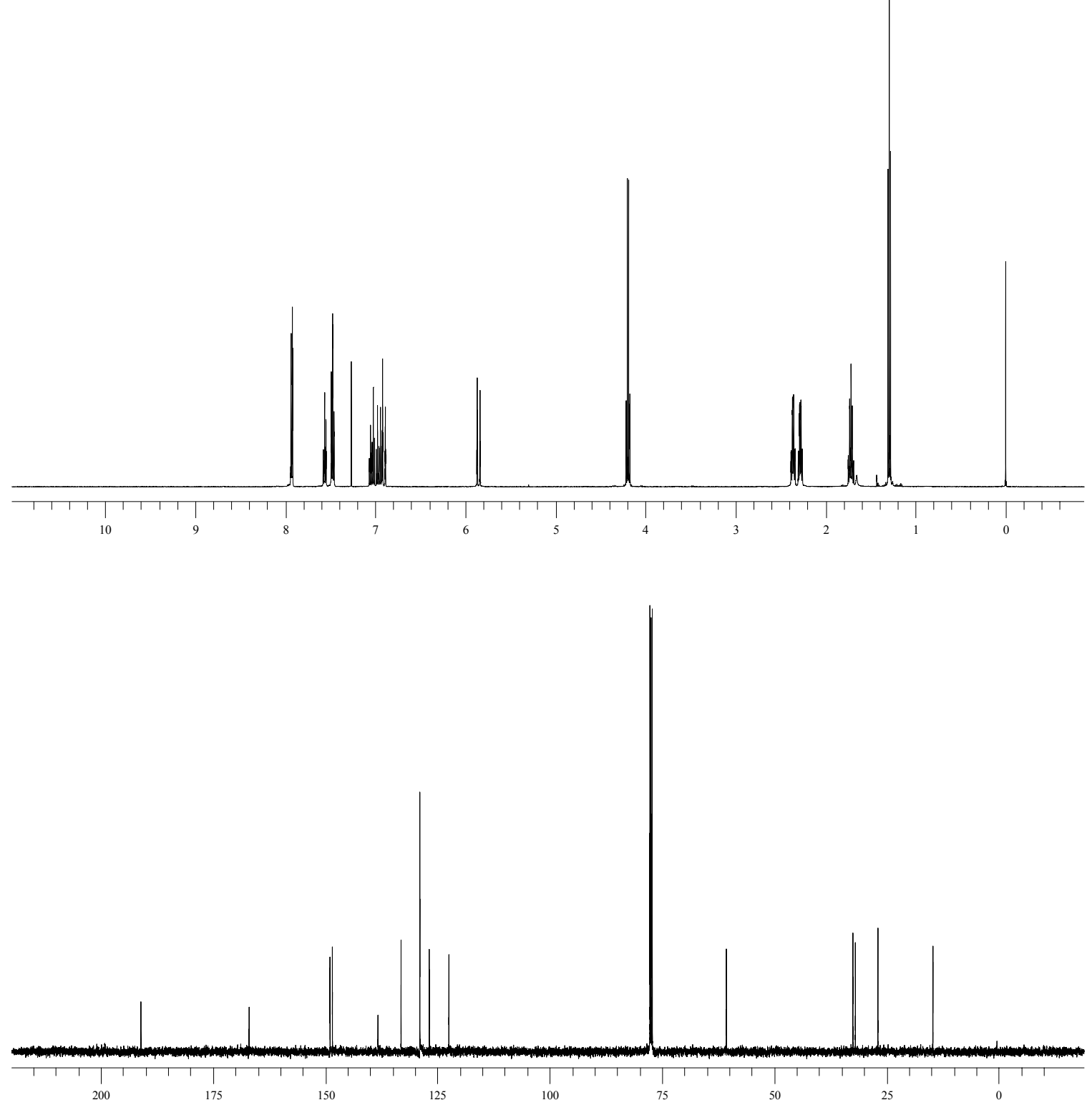

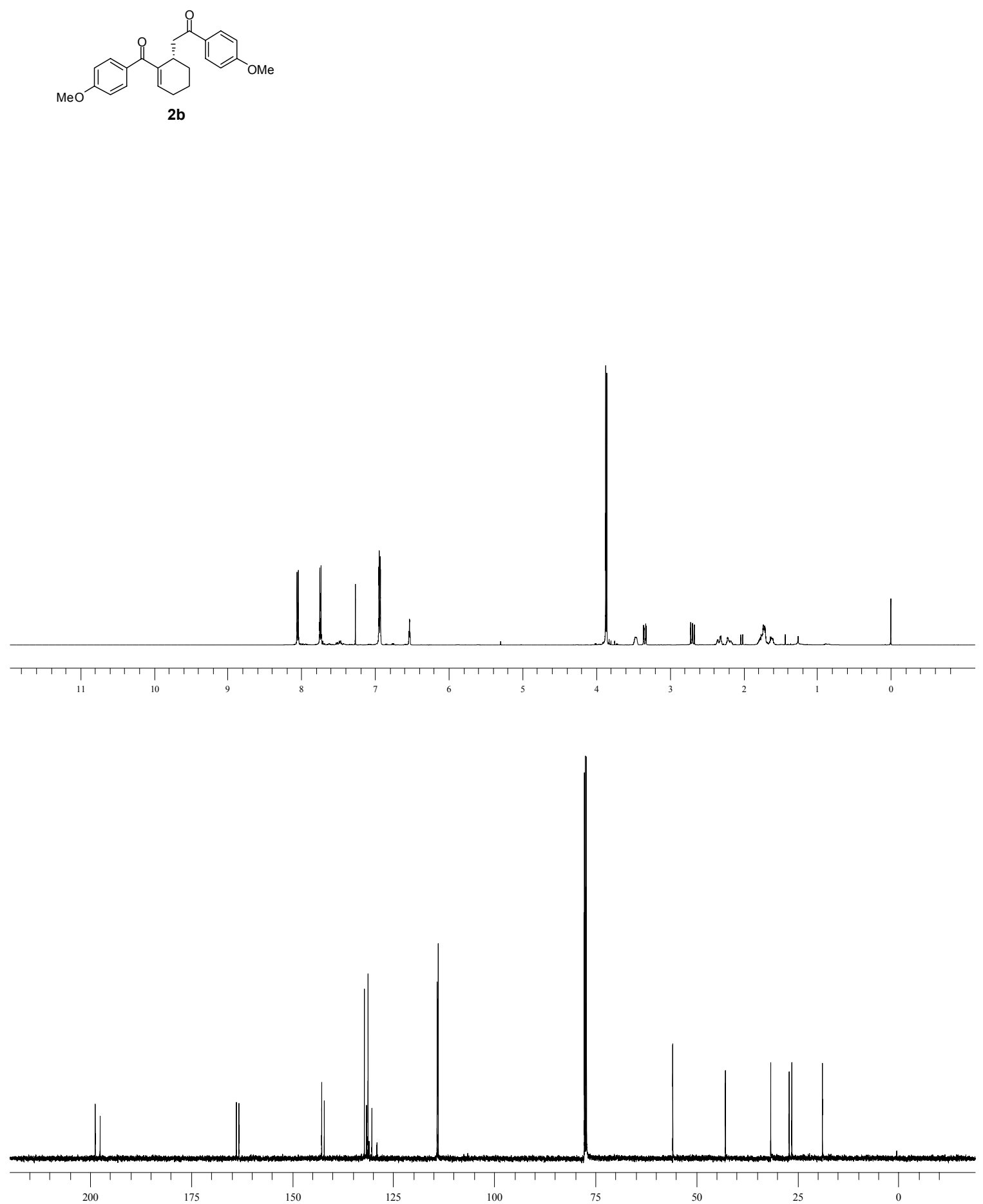

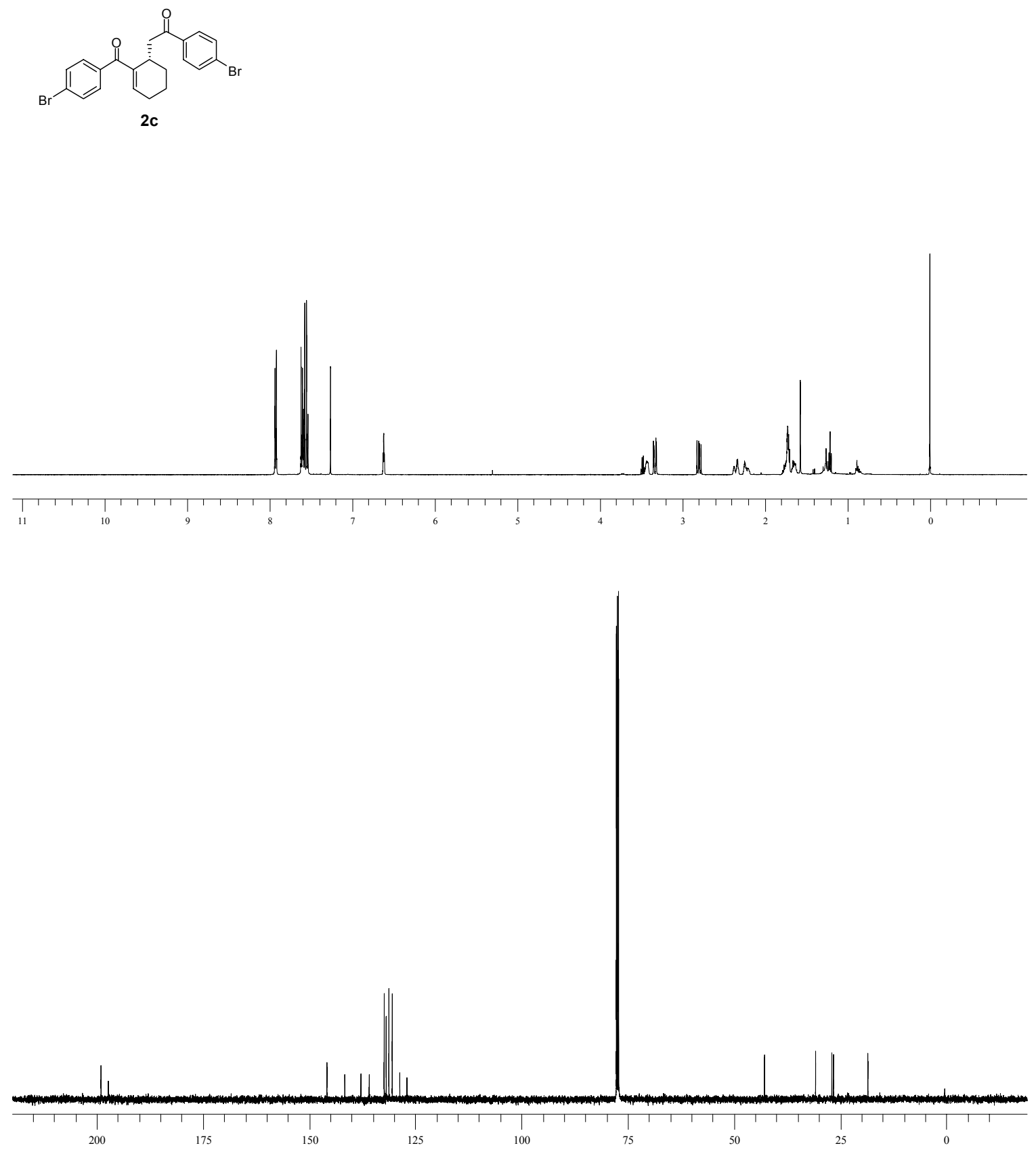

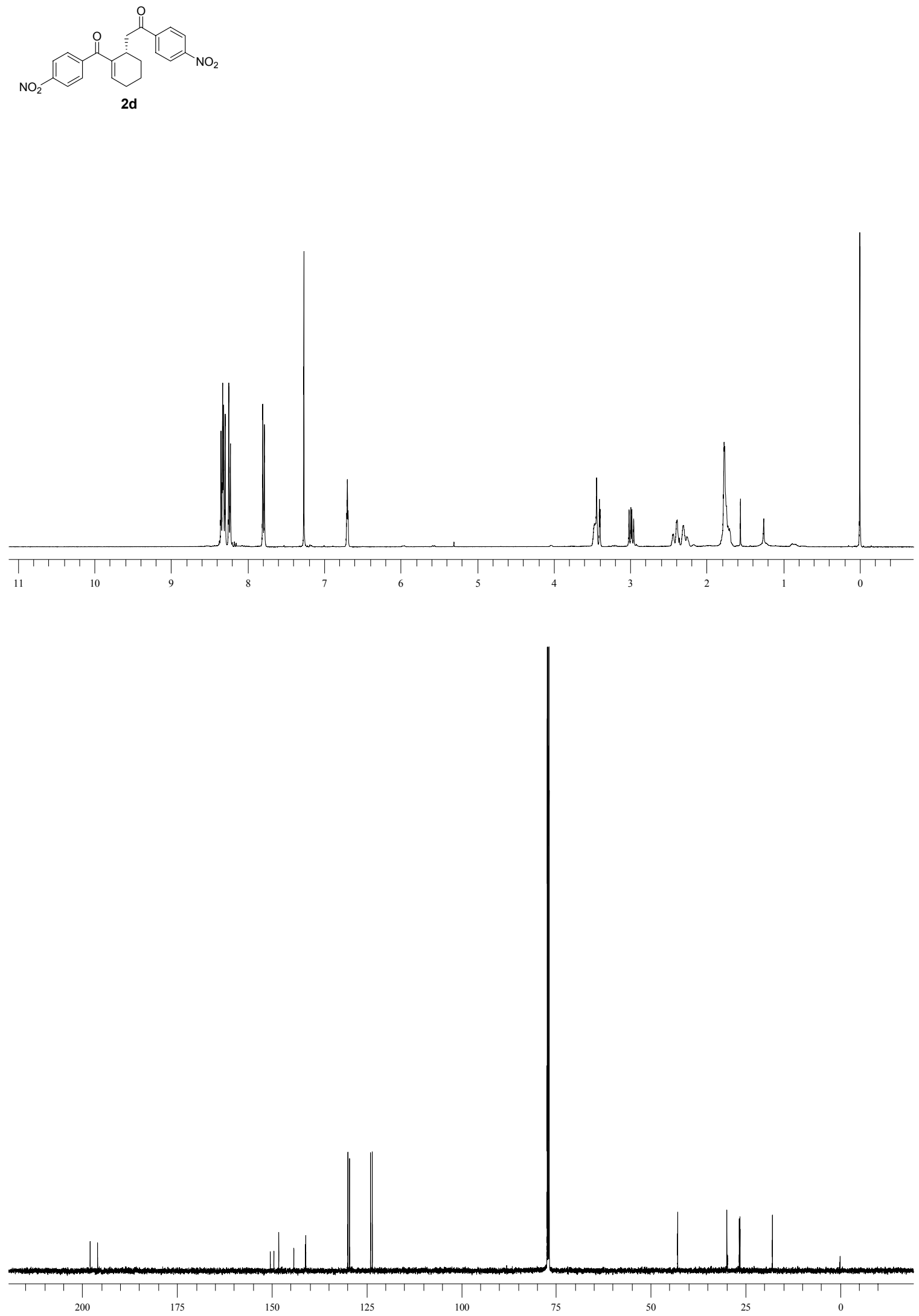

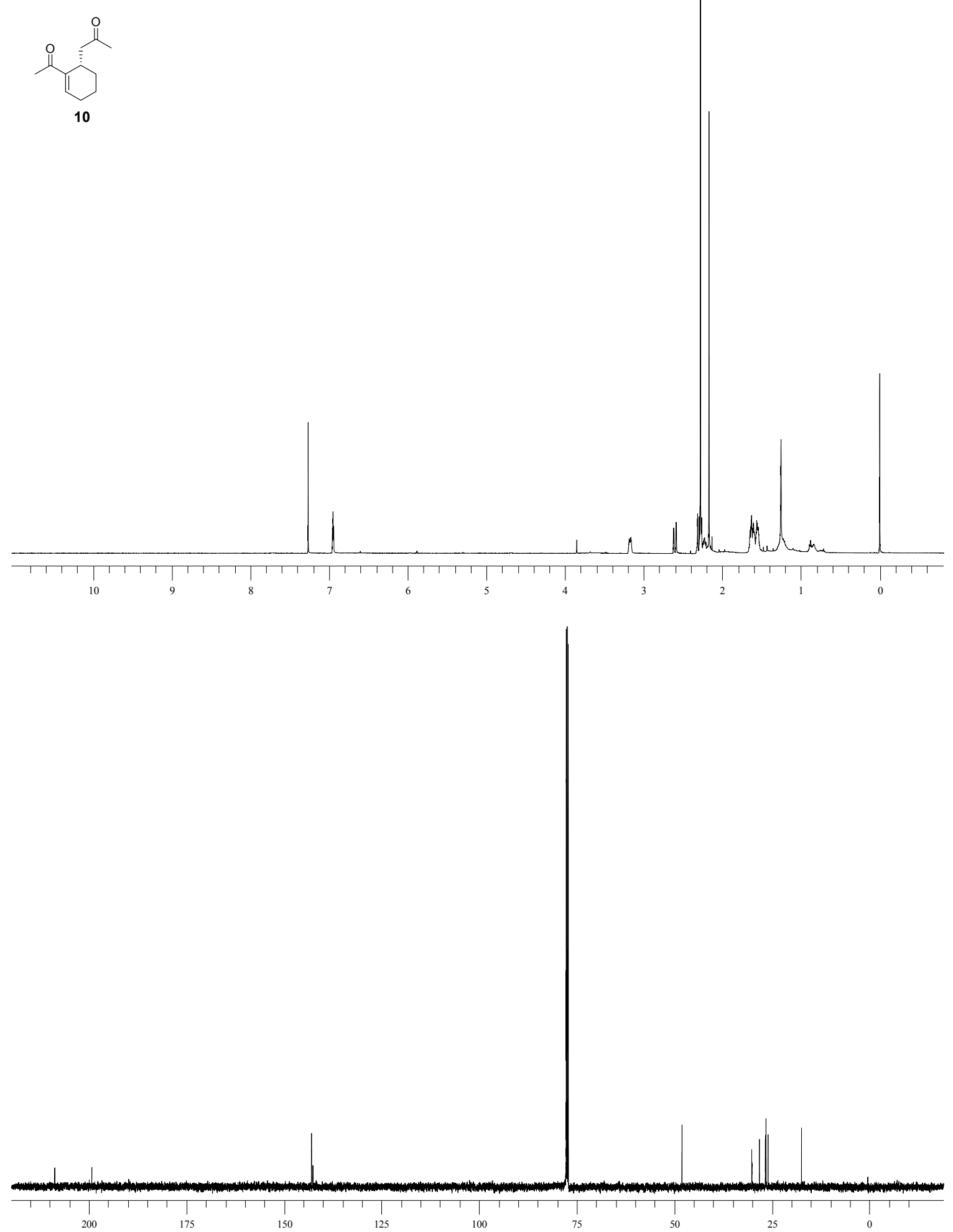

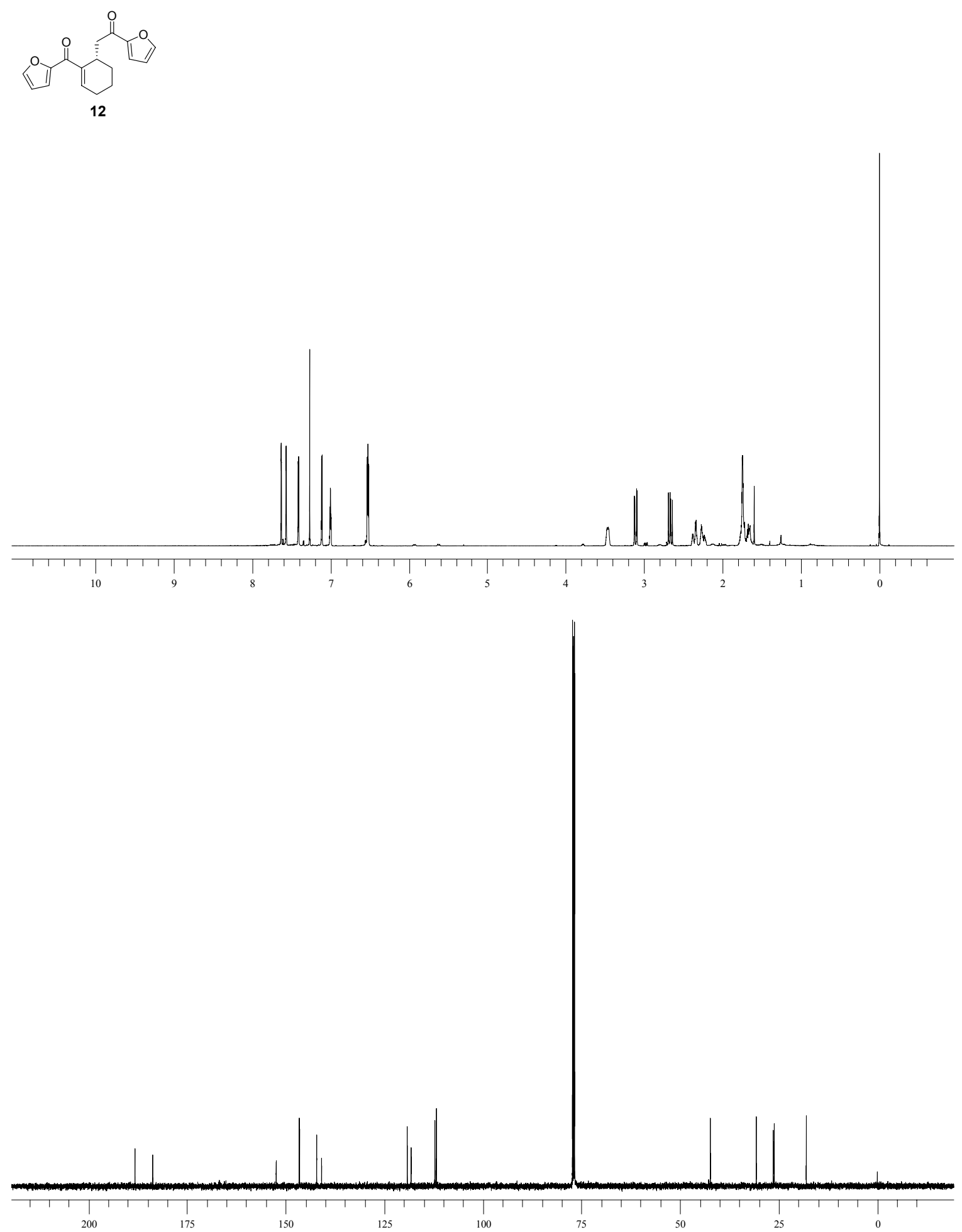

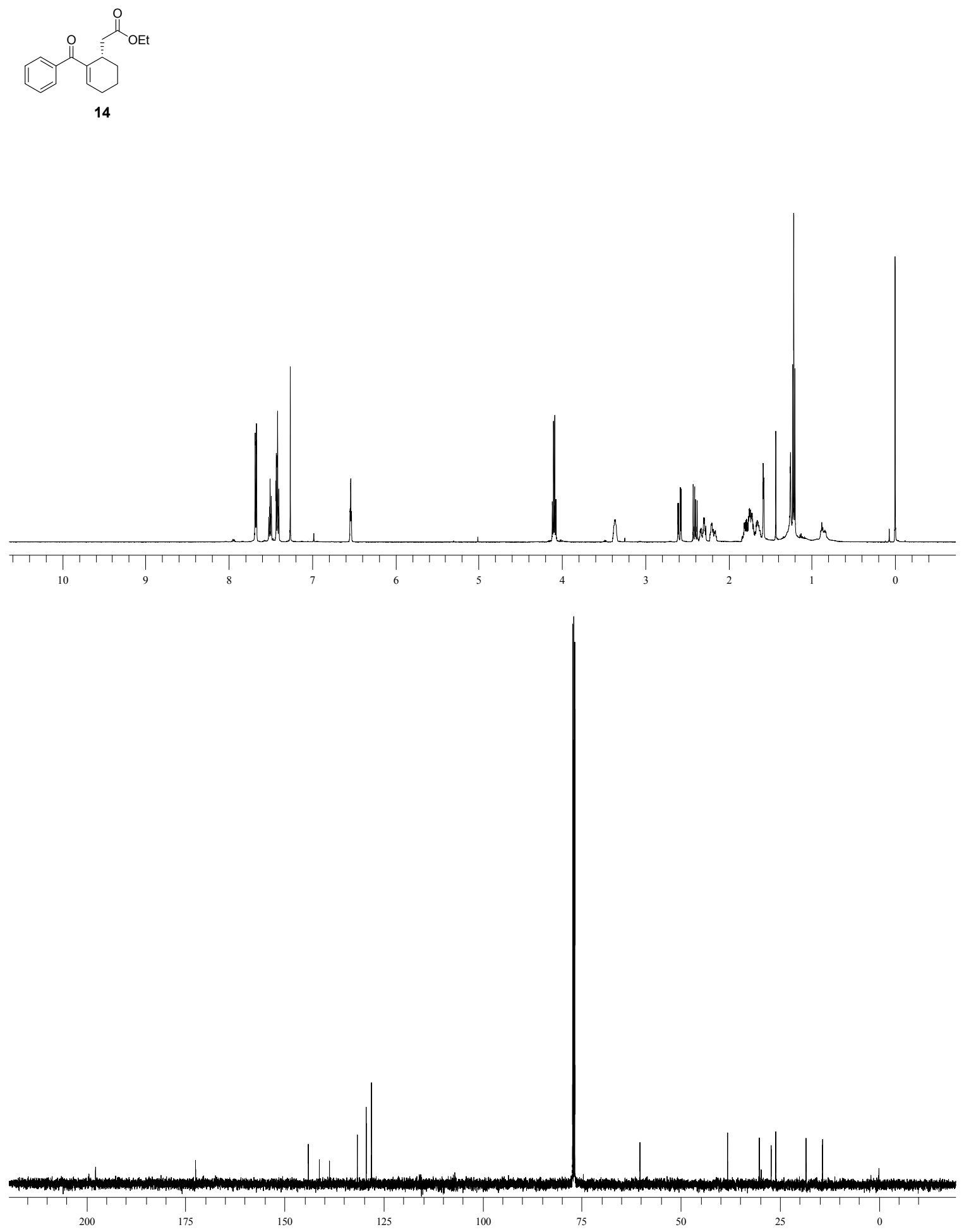

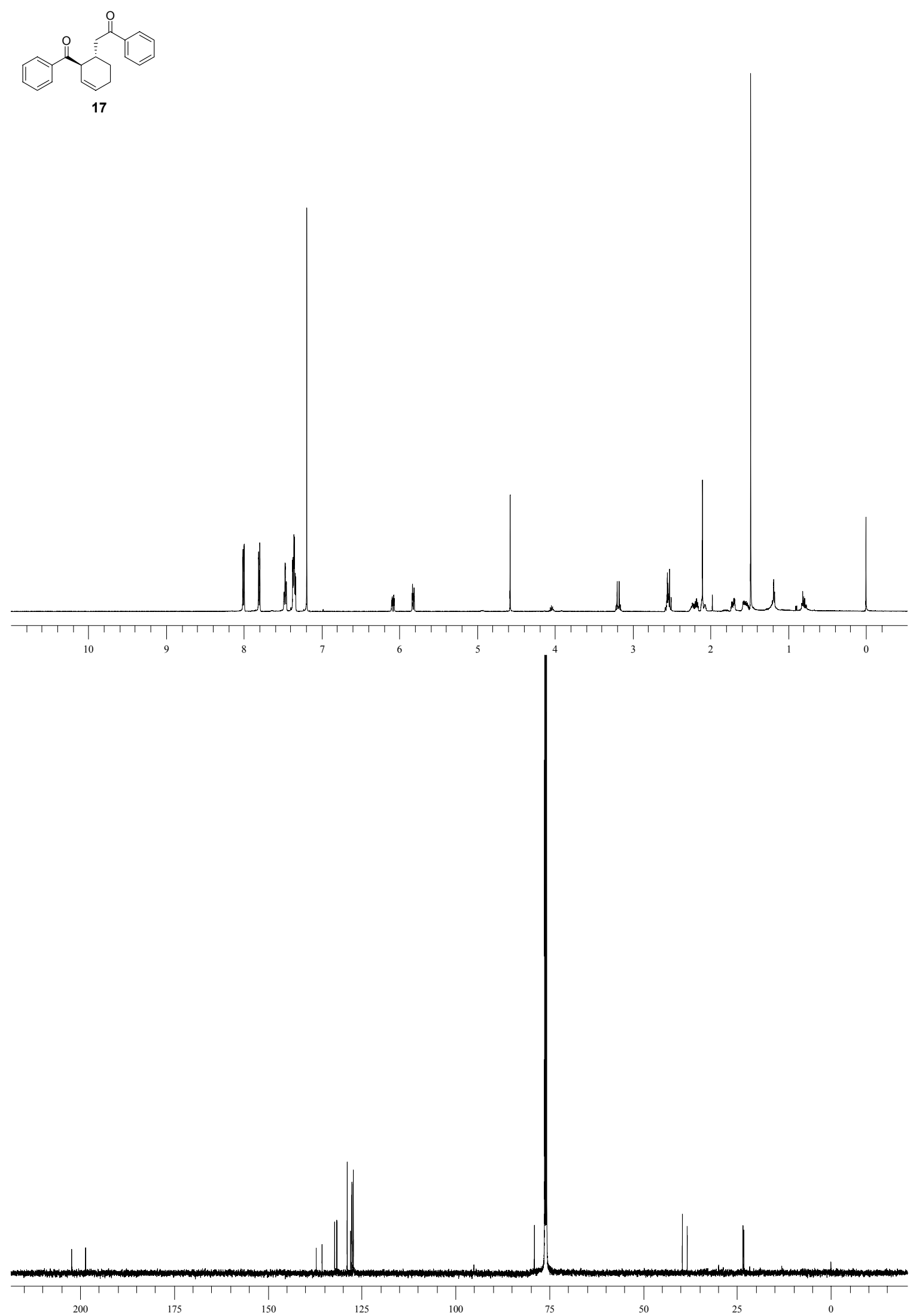

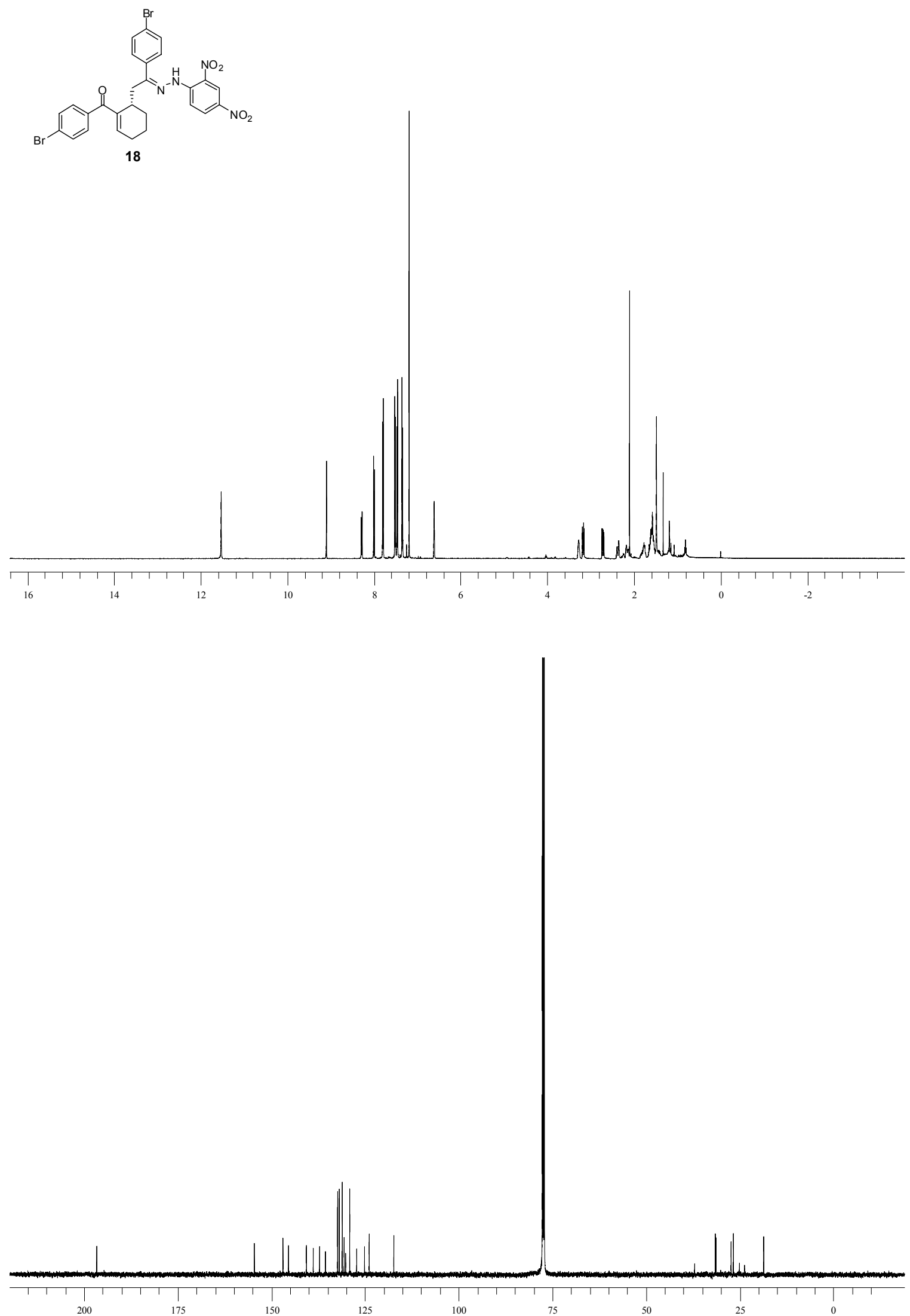


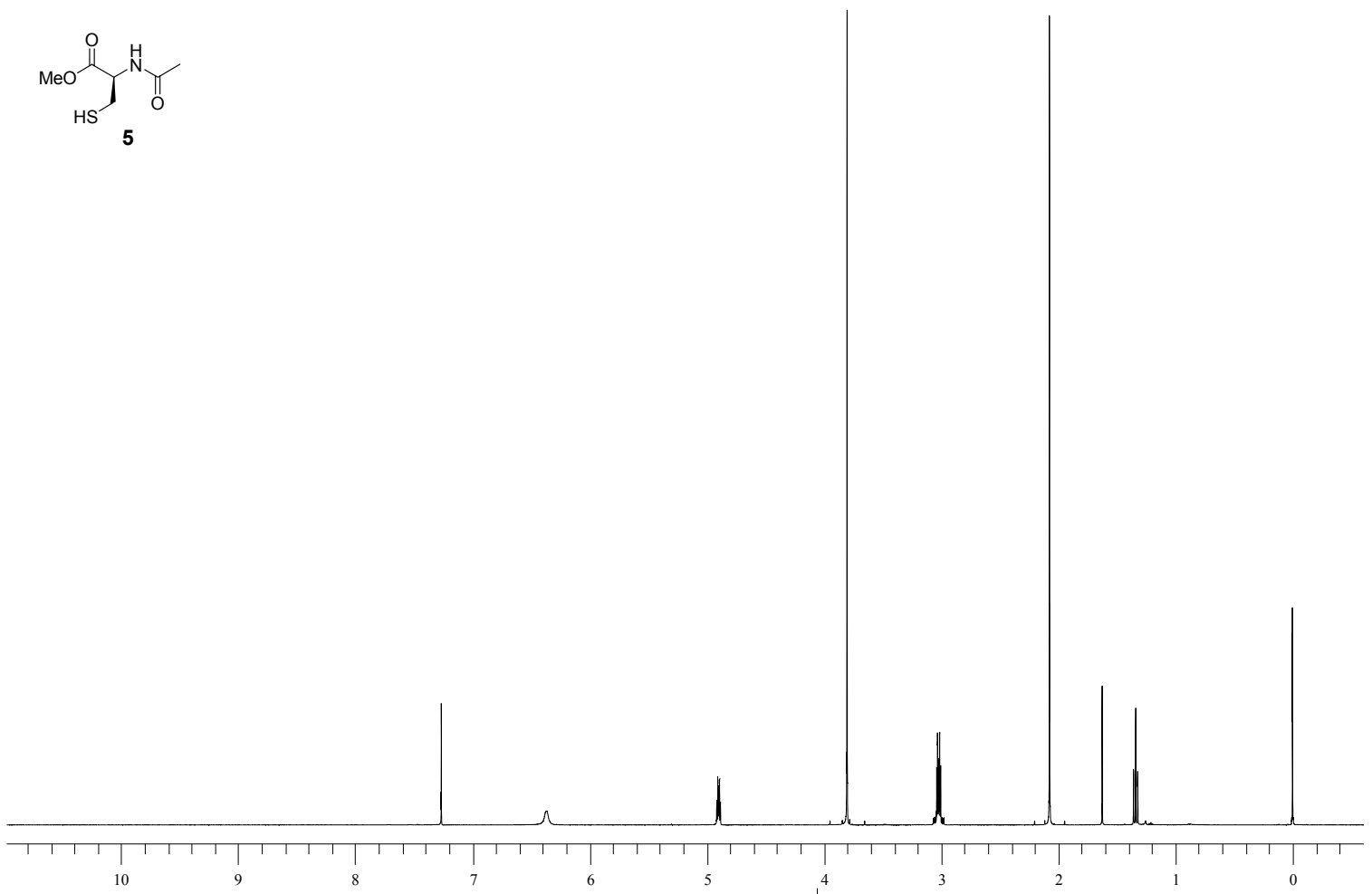

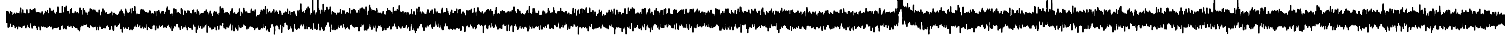



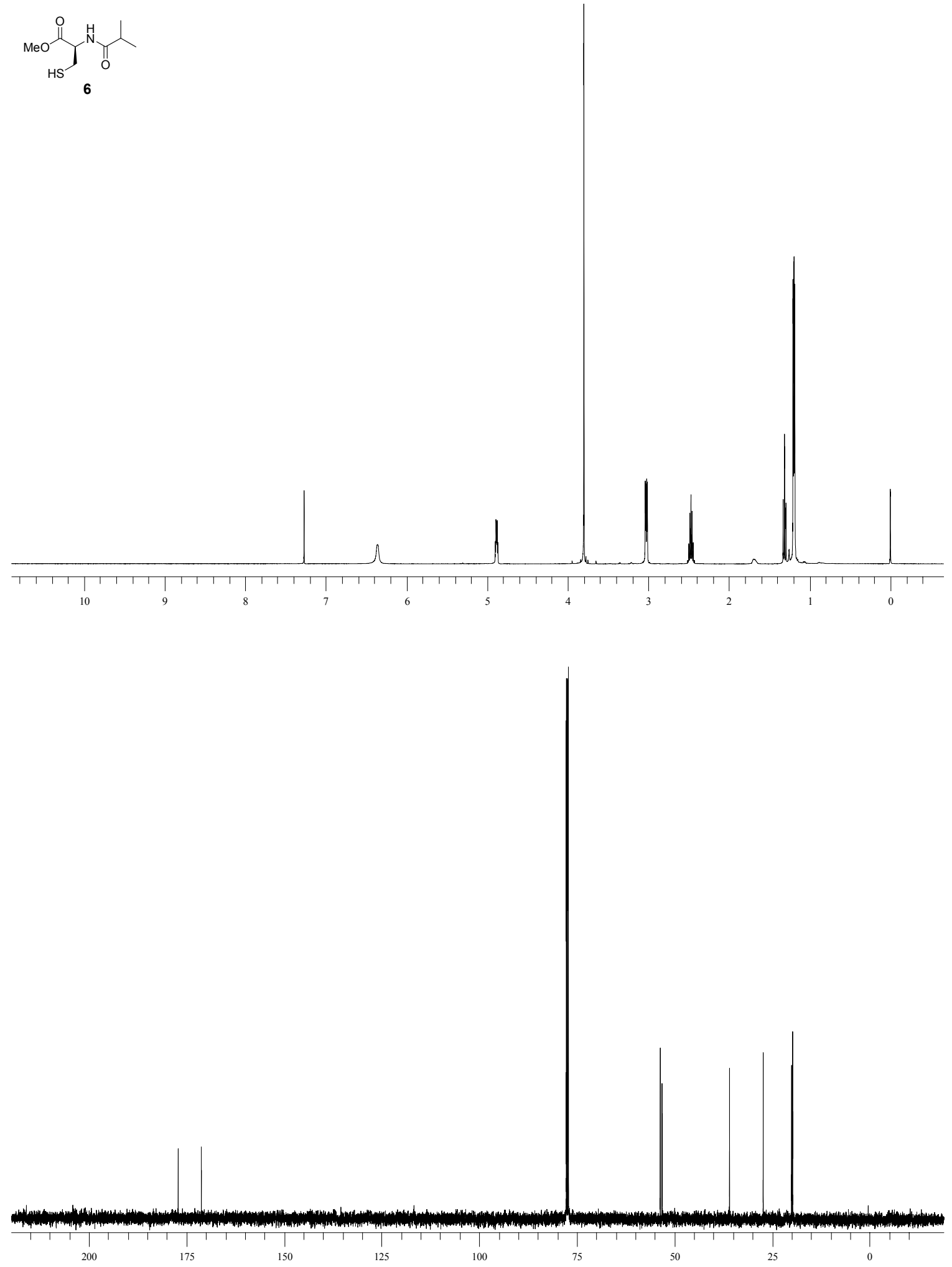

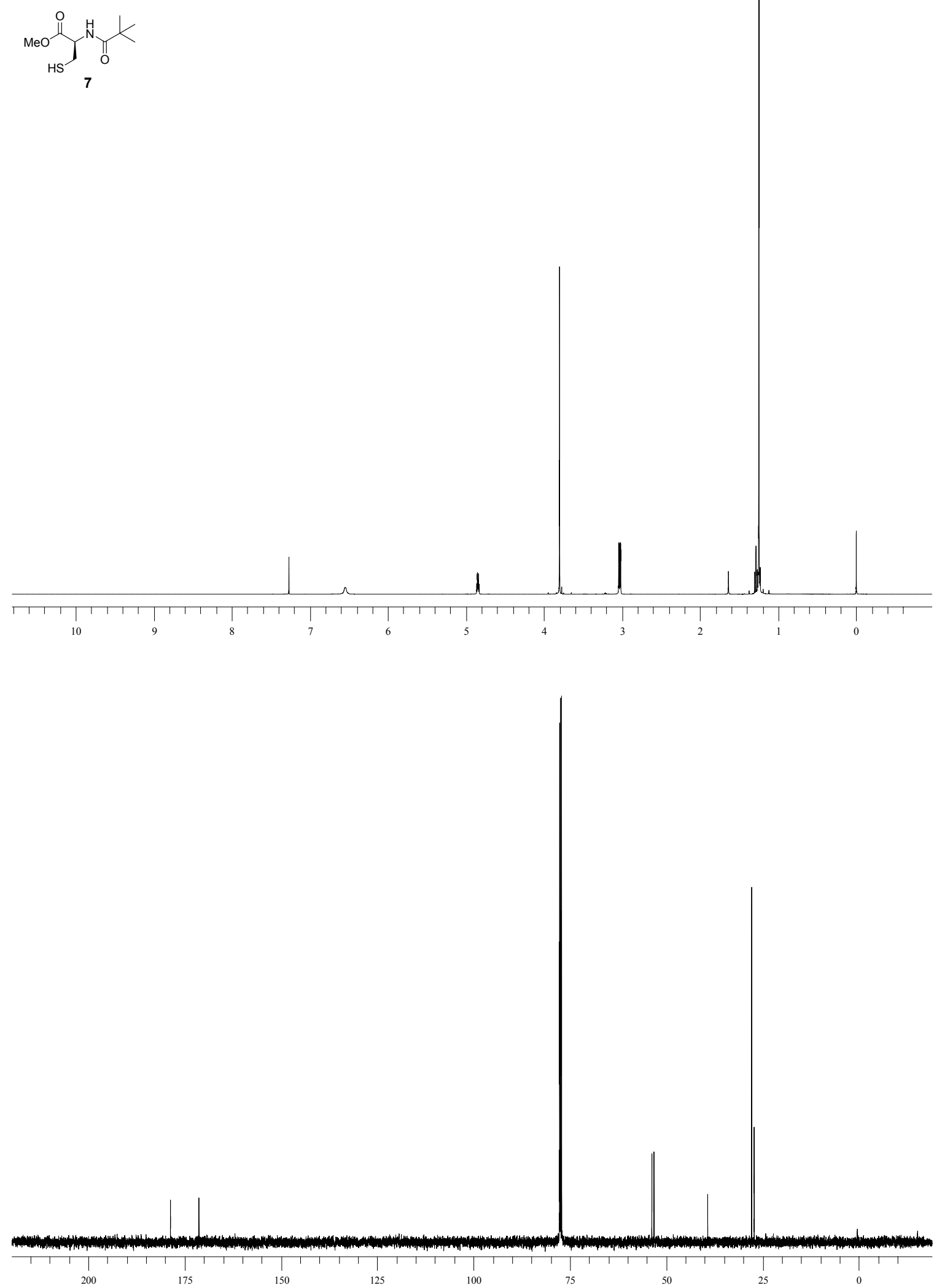
${ }^{\mathrm{i}}$ Still, W.C.; Kahn, M.; Mitra, J. J. Org. Chem. 1978, 43, 2923.

ii (a) Ramirez, F; Dershowitz, S J. Org. Chem. 1957, 22, 41-45. (b) Denney, D.B.; Smith, L.C.; Song, J.; Rossi, C.J.; J. Org. Chem. 1963, 28, 778-780.

iii (a) Wang, L.-C.; Luis, A. L.; Agapiou, K.; Jang, H.-Y.; Krische, M. J. J. Am. Chem. Soc. 2002, 124, 2402-2403. (b) Frank, S. A.; Mergott, D. J.; Roush, W. R. J. Am. Chem. Soc. 2002, 124, 2404-2405.

${ }^{i v}$ Z. Otwinowski and W. Minor, "Processing of X-Ray Diffraction Data Collected in Oscillation Mode," Methods in Enzymology, vol. 276: Macromolecular Crystallography, part A, 307-326, 1997, C.W. Carter, Jr. \& R.M. Sweet, Eds., Academic Press.

${ }^{\vee}$ SHELXTL, v.6.12, Bruker-AXS, Madison, WI, 2001.

${ }^{v i}$ Least Squares function minimized: $\Sigma w\left(\mathrm{~F}_{\mathrm{o}}{ }^{2}-\mathrm{F}_{\mathrm{c}}{ }^{2}\right)^{2}$ 